\title{
Sensitivity analysis to assess the influence of the inertial properties of railway vehicle bodies on the vehicle's dynamic behaviour
}

\author{
B. Suarez, J. Felez, J. Maroto and P. Rodriguez
}

A sensitivity analysis has been performed to assess the influence of the inertial properties of railway vehicles on their dynamic behaviour. To do this, 216 dynamic simulations were performed modifying, one at a time, the masses, moments of inertia and heights of the centre of gravity of the carbody, the bogie and the wheelset. Three values were assigned to each parameter, corresponding to the percentiles 10,50 and 90 of a data set stored in a database of railway vehicles. After processing the results of these simulations, the analysed parameters were sorted by increasing influence. It was also found which of these parameters could be estimated with a lesser degree of accuracy for future simulations without appreciably affecting the simulation results. In general terms, it was concluded that the most sensitive inertial properties are the mass and the vertical moment of inertia, and the least sensitive ones the longitudinal and lateral moments of inertia.

This is an electronic version of an article published in Vehicle System Dynamics,

Vol. 51, No. 2, 2013, pp. 251-279.

VEHICLE SYSTEM DYNAMICS is available online at:

http://www.tandfonline.com/doi/abs/10.1080/00423114.2012.725851

DOI: $10.1080 / 00423114.2012 .725851$

When citing this work, please refer to the published paper:

B. Suarez, J. Felez, J. Maroto and P. Rodriguez, Sensitivity analysis to assess the influence of the inertial properties of railway vehicle bodies on the vehicle's dynamic behaviour. Vehicle System Dynamics, Vol. 51, pp. 251-279. 


\title{
Sensitivity analysis to assess the influence of the inertial properties of railway vehicle bodies on the vehicle's dynamic behaviour
}

\author{
Berta Suarez ${ }^{1}$, Jesus Felez, Joaquin Maroto, Pablo Rodriguez \\ Departamento de Ingeniería Mecánica y Fabricación. Universidad Politécnica de Madrid. \\ ETSI Industriales (CITEF), C/ Jose Gutierrez Abascal, 2, ES-28006 Madrid, SPAIN
}

\begin{abstract}
A sensitivity analysis has been performed to assess the influence of the inertial properties of railway vehicles on their dynamic behaviour. To do this, 216 dynamic simulations were performed modifying, one at a time, the masses, moments of inertia and heights of the centre of gravity of the carbody, the bogie and the wheelset. Three values were assigned to each parameter, corresponding to the percentiles 10,50 and 90 of a data set stored in a database of railway vehicles.

After processing the results of these simulations, the analyzed parameters were sorted by increasing influence. It was also found which of these parameters could be estimated with a lesser degree of accuracy for future simulations without appreciably affecting the simulation results. In general terms, it was concluded that the most sensitive inertial properties are the mass and the vertical moment of inertia, and the least sensitive ones the longitudinal and lateral moments of inertia.
\end{abstract}

Keywords: railway dynamics, sensitivity analysis, dynamic behaviour, mass, moment of inertia, centre of gravity, carbody, bogie, wheelset, safety, track fatigue, ride quality, standard EN-14363, leaflet UIC 518

\section{$1 \quad$ INTRODUCTION}

Usually, when building any model to simulate the dynamic behaviour of a railway vehicle, not all the required data are known. Therefore, a sensitivity study was performed, in order to find the degree of accuracy required in the definition of each vehicle parameter (1).

In particular, it was intended to analyze the influence of the inertial properties of the main bodies of the vehicle (carbody, bogie and wheelset), under different running conditions. This study was complemented with two others, where the influences of the elastic properties of the primary and secondary suspensions (2), as well as that of the rolling features were also analyzed (3).

To consider the influence of the model uncertainties on the vehicle dynamics, a probabilistic approach should be used, as it would predict how the uncertainty of input parameters would be propagated to the model output. A probabilistic method commonly used in such situations is the Monte Carlo simulation, but it requires extremely high computation costs when many uncertain input parameters have to be considered. Other more effective probabilistic methods are sometimes used as, for example, the combination

\footnotetext{
${ }^{1}$ Corresponding autor: Berta Suarez, e-mail: citef-bsuarez@etsii.upm.es,

Postal address: ETSI Industriales (CITEF), C/Jose Gutierrez Abascal, 2, ES-28006 Madrid, SPAIN
} 
of Monte Carlo simulation technique and the design of experiments theory (4) or the generalized polynomial chaos theory (5), though they are also time consuming.

Despite their high computational cost, probabilistic methods should be used whenever quantitative results are required. However, for preliminary research studies, where qualitative results showing the relative importance of the parameters being considered would suffice, simpler methods could be applied. The simplest method consists in modifying input parameters one at a time, thus neglecting any possible relationship that could exist between them. These simplifications make the precision of this method lower than the precision of the previously mentioned probabilistic methods. However, it is very helpful due to its simplicity, which allows analyzing many parameters with a relatively low computational cost, in comparison with the probabilistic methods.

As stated before, the work here exposed is part of a wider study, where the influences of 24 input parameters of the vehicle model were considered: 12 inertial properties of the vehicle bodies, 8 elastic properties of the suspension components and 4 parameters related with the rolling contact. For each parameter, several track layouts and vehicle speeds were also considered. Due to the large number of uncertain input parameters and external conditions to be considered, and having in mind the above mentioned considerations, the simplest approach was chosen for this study. Therefore, the input parameters were modified one at a time, with just three values in each variation, even for parameters with large variation ranges, so assuming that the output quantities are smooth functions of the input parameters.

In view of the above mentioned limiting conditions, the present work could be considered as a starting point, as it would provide a qualitative idea about which influence quantities need to be addressed with particular care when performing simulations addressing a specific problem. From the results obtained, the number of parameters to be considered to undertake in the future a probabilistic approach could be reduced. This way, quantitative and more accurate results could be obtained with a considerable lower computational cost than considering all the uncertain input parameters.

To undertake this work, a reference vehicle model was defined, as described later on in section 3. From this reference model, the values of the inertial properties to be analyzed were independently modified, one at a time. Basically, the inertial properties to be considered for each body are the mass, the moments of inertia and the position of the centre of gravity.

Though the distribution of interior and exterior equipments, as well as the driver cabins, if exist, could make the centre of gravity of the carbody to be displaced from its geometric centre, for this study it was supposed that such deviations are small, due to the symmetry of the carbody. It was also considered that passengers would be homogeneously distributed along the carbody, not modifying such symmetry. Under these hypotheses, the uncertainty of the longitudinal and lateral position of the carbody centre of mass would be lower than the uncertainty attributed to other inertial properties of the vehicle. The same criterion was applied for the bogie and the wheelset. Therefore, both the longitudinal and lateral positions of the centre of gravity of the three bodies were not considered for this study. In the same way, the height of the centre of gravity of the wheelset was also disregarded. The lateral moment of inertia of the wheelset was disregarded, too, as it only affects the rolling of the wheelset over its own axis, which should not affect the running dynamics.

Both the reference model characteristics and the variation ranges assigned to each parameter (6), (7), were assessed from the information stored in a database of railway vehicles, (8), which was specifically built for this purpose. 
A methodology was also developed, to allow a systematic analysis of vehicle dynamic response, thus avoiding to focus on extremely specific cases. With this aim, entirely generic simulation scenarios were defined. In the same way, a systematic statistical treatment was carried out on the simulation results. To define the track layouts and the track qualities to be used in the simulations, the specifications stated in the UIC-518 leaflet (9) and in the European standard EN-14363 (10), generally used for railway vehicles certification by means of on-track tests, were applied in a virtual environment. The same specifications were also used to post-process the results of the simulations. This procedure was chosen for this project because it is well established, supported by many years of experience, and allows the assessment of the vehicle dynamics by means of only a few indexes. These indexes can be compared with some limit values, defined in these standards, in order to find whether the vehicle behaviour is suitable or not from a safety, track fatigue and ride quality point of view.

This methodology allowed the identification of the critical parameters of the simulation models. It also allowed the identification of those inertial properties which could be estimated with lesser accuracy due to their low impact on the accuracy of the simulation results.

\section{BACKGROUND}

This section shows a literature review of various publications presenting the results of several dynamic simulations in which the value of some parameters related with the vehicle inertial properties were modified. The parameters analyzed in each reference are listed below. These bibliographic references were classified according to the type of dynamic study described in each of them. Three types of studies were considered: safety, track fatigue and ride quality. The former, in turn, was also divided into linear stability, non-linear stability and derailment risk studies.

\subsection{SAFETY STUDIES}

Table 1, Table 2 and Table 3 respectively gather some bibliographic references on linear stability, non-linear stability and derailment risk studies.

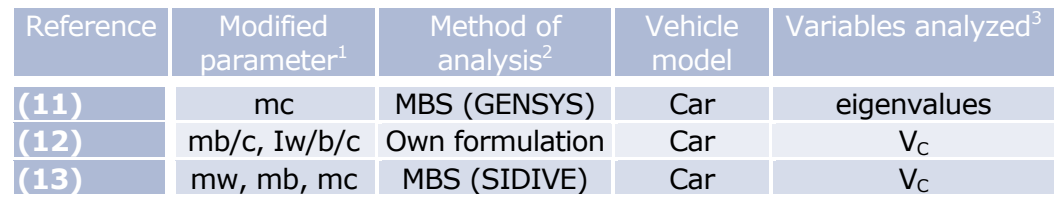

Note $^{(1}:$ m: mass; I: moment of inertia; w: wheelset; b: bogie; c: carbody.

Note (2: MBS: 'Multibody System'; Own formulation: the authors formulate the equations of motion.

Note ${ }^{(3}$ : $V_{C}$ : Critical speed.

TABLE 1 LITERATURE REVIEW: LINEAR STABILITY

\begin{tabular}{|c|c|c|c|c|}
\hline Reference & $\begin{array}{c}\text { Modified } \\
\text { parameter }^{1}\end{array}$ & $\begin{array}{l}\text { Method of } \\
\text { analysis }^{2}\end{array}$ & $\begin{array}{l}\text { Vehicle } \\
\text { model }\end{array}$ & Variables analyzed $^{3}$ \\
\hline$(14)$ & $\mathrm{mw}, \mathrm{mb}$ & Own formulation & Bogie & $\mathrm{V}_{\mathrm{C}}$ \\
\hline (15) & Mc & MBS (GENSYS) & Car & ay carbody \\
\hline (16) & Mc & Own formulation & Car & $\mathrm{V}_{\mathrm{C}}$ \\
\hline$(17)$ & Mw & Own formulation & Bogie & y wheelset, y b \\
\hline
\end{tabular}

Note $^{(1}$ : m: mass; I: moment of inertia; w: wheelset; b: bogie; c: carbody.

Note (2: MBS: 'Multibody System'; Own formulation: the authors formulate the equations of motion.

Note ${ }^{3}$ : $V_{C}$ : Critical speed; a: acceleration.

TABLE 2 LITERATURE REVIEW: NON-LINEAR STABILITY 


\begin{tabular}{|c|c|c|c|c|}
\hline Reference & Modified parameter & $\begin{array}{l}\text { Method of } \\
\text { analysis }^{2}\end{array}$ & $\begin{array}{l}\text { Vehicle } \\
\text { model }\end{array}$ & Variables analyzed ${ }^{3}$ \\
\hline (18) & Mc & Own formulation & Car & $\mathrm{Y} / \mathrm{Q}$ \\
\hline (19) & $\mathrm{mc}$ & Own formulation & Car & $\mathrm{Y} / \mathrm{Q}$ \\
\hline (20) & $\mathrm{mw} / \mathrm{b} / \mathrm{c}, \mathrm{Iw} / \mathrm{b} / \mathrm{c}$ & MBS (A'GEM) & Car & $\mathrm{Y} / \mathrm{Q}$ \\
\hline (21) & Ixc & MBS (SIMPACK) & Car & $\Delta \mathrm{Q}_{/} \mathrm{Q}_{0}$ \\
\hline (22) & $\mathrm{mc}$ & MBS (RT Vampire) & Car & $\mathrm{Y} / \mathrm{Q}, \Delta \mathrm{Q} / \mathrm{Q}_{0}, \mathrm{z}$ wheel \\
\hline (23) & $\mathrm{mc}$ & Own formulation & Train & F coupling \\
\hline
\end{tabular}

Note ${ }^{1}$ : m: mass; I: moment of inertia; w: wheelset; b: bogie; c: carbody; x: longitudinal direction.

Note (2: MBS: 'Multibody System'; Own formulation: the authors formulate the equations of motion.

Note (3: Y(Q): wheel lateral (vertical) load; F: force.

TABLE 3 LITERATURE REVIEW: DERAILMENT RISK

\subsection{Track fatigue studies}

Table 4 gathers some bibliographic references on track fatigue.

\begin{tabular}{|c|c|c|c|c|}
\hline Reference & $\begin{array}{l}\text { Modified } \\
\text { parameter }^{1}\end{array}$ & $\begin{array}{l}\text { Method of } \\
\text { analysis }^{2}\end{array}$ & $\begin{array}{l}\text { Vehicle } \\
\text { model }\end{array}$ & Variables analyzed ${ }^{3}$ \\
\hline (24) & $\mathrm{mw}$ & Own formulation & Bogie & $\mathrm{Q}$ \\
\hline (25) & $\mathrm{mc}$ & Own formulation & Wheelset & Q \\
\hline (26) & $\mathrm{Q}_{0}, \mathrm{zGc}$ & MBS (GENSYS) & Car & $\mathrm{Q}, \mathrm{z}$ track \\
\hline
\end{tabular}

Note ${ }^{1}:$ m: mass; G: centre of gravity; w: wheelset; carbody; $Q_{0}$ : axle load.

Note (2: MBS: 'Multibody System'; Own formulation: the authors formulate the equations of motion.

Note ${ }^{3}$ : Q: wheel vertical load.

TABLE 4 LITERATURE REVIEW: TRACK FATIGUE

\subsection{RIDE QUALITY STUDIES}

Table 5 gathers some bibliographic references on ride quality.

Note (2: FEM: 'Finite Element Method'; MBS: 'Multibody System'; Own formulation: the authors formulate the equations of motion.

Note (3: a: acceleration; Wz: Sperling's index; $\Delta z 1$ (2): deflection of primary(secondary) suspension.

\section{TABLE 5 LITERATURE REVIEW: RIDE QUALITY}

\subsection{Compensation OF THE NOTED DEFICIENCIES}

It can be seen that references analyzing the sensitivity of the inertial properties of vehicle bodies are quite rare. These analyses are usually limited to variations of the mass of the bodies, with the influence of other inertial properties rarely being considered, such as the moments of inertia or the position of the centre of gravity. Moreover, except in stability studies, in which the behaviour of the un-sprung mass is taken into account, these works are usually focused on the inertial properties of the carbody.

All these references generally show very specific applications, focused on the study of a given vehicle, running over small track sections with simple geometry. They are also generally focused either on stability, on curve negotiation or on comfort studies, but seldom on the three types of study simultaneously. On the other hand, the range of values considered for the variability of each parameter is generally arbitrary, showing high variability from one study to another.

This study intends to extend the scope of the previous works, trying to cover as many parameters of interest as possible. For each parameter it is also intended to cover a range 
of values wide enough to consider many of the possible values that could be found in different railway vehicles.

Unlike the previous works, this study presents a more comprehensive approach, trying to simultaneously analyze the influence of all the different inertial properties of the vehicle to assess their impact on safety, track fatigue and ride quality, so making it possible to determine which of these studies is more critical.

The same reference vehicle was employed to analyze the influence of all vehicle parameters, (2) and (3). Three realistic track layouts were also used, with a cumulative length of $35 \mathrm{~km}$, covering a wide range of curve radii. In the same way, three different running speeds were considered for each track layout.

In this way, it was intended to provide a wider view when analyzing the influence of the inertial properties of bodies to assess their impact on the vehicle dynamics.

\section{Set-up of the Reference model}

To perform the sensitivity analysis, multibody system (MBS) simulation techniques were employed. In particular, the SIMPACK commercial program was used. It allows simulating multi-body systems with especial features related with railway vehicle models, as the longitudinal guidance and the wheel-rail contact, which involves great forces transmitted through a small surface. SIMPACK has been tested in several benchmarks, as the Manchester benchmarks for railway vehicle dynamics (30), the ERRI Benchmark (31) or the Volpe LD benchmark (32).

In the following, the main features of the reference model used in the simulations are described.

\subsection{DEFINITION OF THE PARAMETERIZED VEHICLE}

The vehicle model used in this study represents a passenger car with two bogies, with the carbody resting on the elastic elements of the secondary suspension without any pivot or centre plate.

A reference system, $x y z$, was defined, with $\mathrm{x}$ positive forwards, y positive rightwards and $z$ positive downwards. It follows the track centreline with the speed of the vehicle.

The main bodies of the vehicle (carbody, bogie frames and wheelsets) were modeled as rigid bodies, connected to each other by means of linear springs and dampers that characterize the primary and secondary suspensions. Figure 1 depicts the topological diagram of the complete model.

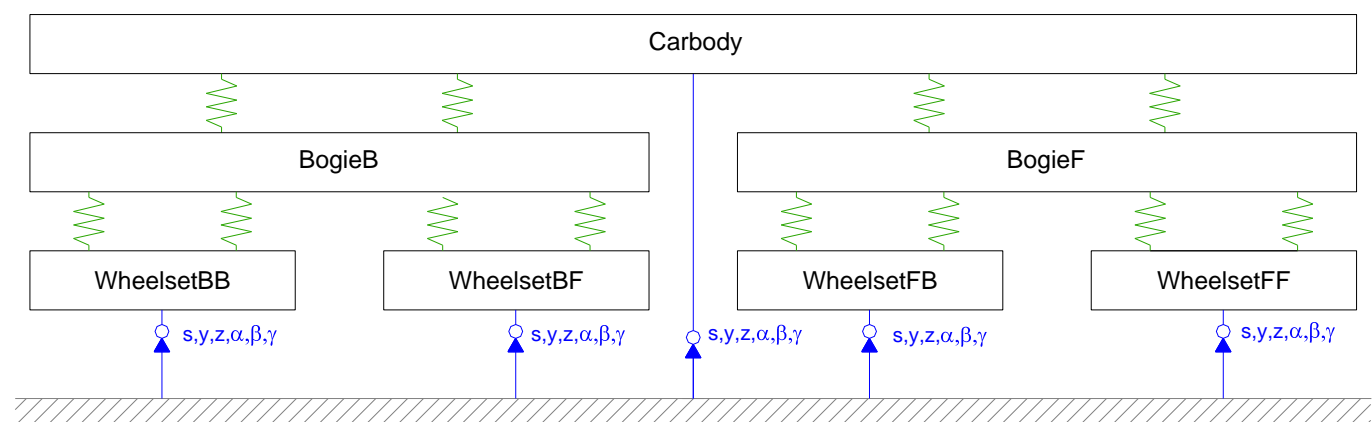

Reference: "WIIIIIIIIIIIIIIIIII, Body: $\quad$ Body $\quad$ Joint: $\longrightarrow$ Force element: $\longrightarrow$ Degrees of freedom: $x=$ along the track; $y=$ lateral; $z=$ vertical; $\alpha=$ roll; $\beta=$ pitch; $\gamma=$ yaw.

FIGURE 1 TOPOLOGICAL DIAGRAM OF THE VEHICLE MODEL 
The vehicle model was parameterized with the aim of easing the variation of its features during the subsequent sensitivity analysis. Over 160 parameters were used (Table 6).

\begin{tabular}{|lc|}
\hline \multicolumn{1}{|c|}{ Parameters } & Number \\
\hline Inertial properties of bodies & 35 \\
\hline Elastic properties of suspensions & 12 \\
\hline Elastic properties of the coupling system & 9 \\
\hline Carbody and bogie wheelbases & 2 \\
\hline Dimensions for the graphical representation of bodies & 48 \\
\hline Position of bodies for its graphical representation & 30 \\
\hline Position of suspension elements & 12 \\
\hline Position of the coupling elements & 15 \\
\hline
\end{tabular}

TABLE 6 PARAMETERS USED IN THE MODEL

The vehicle model was built from smaller models of the individual components of the vehicle (carbody, bogie, primary suspension and secondary suspension). These submodels are reusable and are assembled into the whole vehicle model.

Figure 2 shows a snapshot of the vehicle model, after finishing the set-up process.

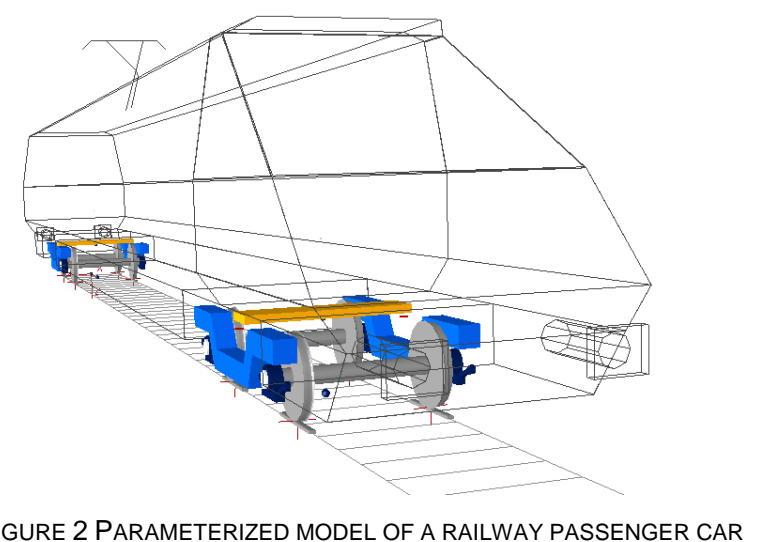

After defining the model topology, numerical values were assigned to the different model parameters. Table 7 and Table 8 respectively gather the values used in the reference vehicle model for the inertial properties of the vehicle bodies and for the elastic properties of the vehicle suspensions. 


\begin{tabular}{|c|c|c|c|}
\hline & Parameter $^{1}$ & Unit & Median \\
\hline & M & [kg] & $37.3 \cdot 10^{3}$ \\
\hline & Ixx & {$\left[\mathrm{kg} \cdot \mathrm{m}^{2}\right]$} & $55.5 \cdot 10^{3}$ \\
\hline & Iyy & {$\left[\mathrm{kg} \cdot \mathrm{m}^{2}\right]$} & $1.82 \cdot 10^{6}$ \\
\hline & Izz & {$\left[\mathrm{kg} \cdot \mathrm{m}^{2}\right]$} & $1.78 \cdot 10^{6}$ \\
\hline & $\operatorname{cog} \_z$ & {$[\mathrm{~m}]$} & $1.79 \cdot 10^{\circ}$ \\
\hline & Lx & [m] & $17.6 \cdot 10^{0}$ \\
\hline & M & {$[\mathrm{kg}]$} & $3.13 \cdot 10^{3}$ \\
\hline & Ixx & {$\left[\mathrm{kg} \cdot \mathrm{m}^{2}\right]$} & $1.80 \cdot 10^{3}$ \\
\hline & Iyy & {$\left[\mathrm{kg} \cdot \mathrm{m}^{2}\right]$} & $2.20 \cdot 10^{3}$ \\
\hline & Izz & {$\left[\mathrm{kg} \cdot \mathrm{m}^{2}\right]$} & $3.37 \cdot 10^{3}$ \\
\hline & $\operatorname{cog} \_z$ & [m] & $610 \cdot 10^{-3}$ \\
\hline & Lx & [m] & $2.60 \cdot 10^{\circ}$ \\
\hline & M & {$[\mathrm{kg}]$} & $1.72 \cdot 10^{3}$ \\
\hline & Ixx/Izz & {$\left[\mathrm{kg} \cdot \mathrm{m}^{2}\right]$} & $860 \cdot 10^{0}$ \\
\hline & Iyy & {$\left[\mathrm{kg} \cdot \mathrm{m}^{2}\right]$} & $140 \cdot 10^{0}$ \\
\hline & $\operatorname{cog} \_z$ & [m] & $460 \cdot 10^{-3}$ \\
\hline & ro & [m] & $460 \cdot 10^{-3}$ \\
\hline
\end{tabular}

Note ${ }^{(1}:$ M: mass; Ijj: moment of inertia around the j axis; $\operatorname{cog}_{-}$z: vertical position of the centre of gravity; Lx: distance between pivots of bogies (for carbody) or wheelbase (for bogie); r0: rolling radius.

TABLE 7 MEDIAN VALUes OF BOdY PARAMETERS

\begin{tabular}{|c|c|c|c|}
\hline & Parameter ${ }^{1}$ & Unit & Median \\
\hline \multirow{6}{*}{ 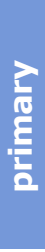 } & $\mathrm{kx}$ & {$[\mathrm{N} / \mathrm{m}]$} & $5.20 \cdot 10^{6}$ \\
\hline & ky & {$[\mathrm{N} / \mathrm{m}]$} & $4.55 \cdot 10^{6}$ \\
\hline & kz & {$[\mathrm{N} / \mathrm{m}]$} & $1.17 \cdot 10^{6}$ \\
\hline & $d x$ & {$[\mathrm{~N} \cdot \mathrm{s} / \mathrm{m}]$} & $1.98 \cdot 10^{3}$ \\
\hline & dy & {$[\mathrm{N} \cdot \mathrm{s} / \mathrm{m}]$} & $2.86 \cdot 10^{3}$ \\
\hline & $\mathrm{dz}$ & {$[\mathrm{N} \cdot \mathrm{s} / \mathrm{m}]$} & $12.0 \cdot 10^{3}$ \\
\hline \multirow{6}{*}{$\begin{array}{l}\frac{7}{5} \\
\frac{10}{0} \\
\frac{8}{8} \\
8 \\
\text { ํ. }\end{array}$} & $k x$ & {$[\mathrm{~N} / \mathrm{m}]$} & $170 \cdot 10^{3}$ \\
\hline & ky & {$[\mathrm{N} / \mathrm{m}]$} & $250 \cdot 10^{3}$ \\
\hline & kz & {$[\mathrm{N} / \mathrm{m}]$} & $560 \cdot 10^{3}$ \\
\hline & $d x$ & {$[\mathrm{~N} \cdot \mathrm{s} / \mathrm{m}]$} & - \\
\hline & dy & {$[\mathrm{N} \cdot \mathrm{s} / \mathrm{m}]$} & $22.5 \cdot 10^{3}$ \\
\hline & $\mathrm{dz}$ & {$[\mathrm{N} \cdot \mathrm{s} / \mathrm{m}]$} & $27.0 \cdot 10^{3}$ \\
\hline
\end{tabular}

Note ${ }^{1}$ : kj: stiffness along the $\mathrm{j}$ axis; dj: damping along the $\mathrm{j}$ axis.

TABLE 8 MEDIAN VALUES OF SUSPENSION PARAMETERS

These values were obtained from the median values of the data stored in the RVDynDB database, specifically made for this purpose (6), (7). It should be noted that both the inertial properties and the elastic properties were extracted from the database following the same criteria, despite the latter were not analyzed in this study.

At a first glance, a median value of $1720 \mathrm{~kg}$ for the mass of a single wheelset may seem quite high, as a $50 \%$ of the values stored in the database are higher than this value. Though it is not specified in the sources from which that values were extracted, most of these high values would probably consider the un-sprung mass together with the wheelset mass, so including the masses of brake disks, which could be important for high speed vehicles, as well as the proportional part of the axle boxes and other primary suspension components.

As the fictitious vehicle so defined could exhibit a dynamic behaviour different from that of a real vehicle, multidimensional scaling techniques were used to select those database records closer to this median vehicle. Seven candidates to be the reference vehicle were identified, whose dynamic behaviour was simulated. From those, the reference vehicle was 
chosen as that which, showing an adequate dynamic behaviour, requires the smallest computational effort in the simulations. This reference vehicle happened to be the median vehicle, which is especially well suited for the further sensitivity study, by avoiding that some parameters of the reference vehicle could be close to any of the ends of the variation ranges used for the sensitivity analysis of the considered parameter.

\subsection{DEFINITION OF TRACK MODELS}

Table 9, Table 10 and Table 11 gather the specific features of each layout (length of straight sections, curves and transition curves; curve radius and cant).

\begin{tabular}{|c|c|c|c|c|c|}
\hline \multicolumn{7}{|c|}{ RL track layout } \\
\hline$\#$ & $\begin{array}{c}\text { L straight } \\
{[\mathrm{m}]}\end{array}$ & $\begin{array}{c}\mathrm{L} \text { transition } \\
{[\mathrm{m}]}\end{array}$ & $\begin{array}{c}\mathrm{L} \text { curve } \\
{[\mathrm{m}]}\end{array}$ & $\begin{array}{c}\text { Radius }^{1} \\
{[\mathrm{~m}]}\end{array}$ & $\begin{array}{c}\text { Cant }^{1} \\
{[\mathrm{~m}]}\end{array}$ \\
\hline $\mathbf{1}$ & 400 & 84 & 800 & 1800 & 0.060 \\
\hline $\mathbf{2}$ & 500 & 126 & 1000 & -1630 & -0.090 \\
\hline $\mathbf{3}$ & 200 & 112 & 1000 & -1900 & -0.080 \\
\hline $\mathbf{4}$ & 348 & 112 & 600 & -1700 & -0.080 \\
\hline $\mathbf{5}$ & 200 & 126 & 800 & 1640 & 0.090 \\
\hline $\mathbf{6}$ & 100 & 84 & 600 & 1800 & 0.060 \\
\hline $\mathbf{7}$ & 170 & 84 & 500 & 1950 & 0.060 \\
\hline $\mathbf{8}$ & 120 & 112 & 1000 & -1700 & -0.080 \\
\hline $\mathbf{9}$ & 255 & 84 & 600 & 1620 & 0.060 \\
\hline $\mathbf{1 0}$ & 320 & 112 & 400 & -1650 & -0.080 \\
\hline
\end{tabular}

Note ${ }^{1}$ : Positive values used for right-handed curves and negative values for left-handed curves.

\begin{tabular}{|c|c|c|c|c|c|}
\hline \multicolumn{7}{|c|}{ TABLE 9 RL LAYOUT SECTIONS $^{\text {RM track layout }}$} \\
\hline$\#$ & $\begin{array}{c}\text { L straight } \\
{[\mathrm{m}]}\end{array}$ & $\begin{array}{c}\text { L transition } \\
{[\mathrm{m}]}\end{array}$ & $\begin{array}{c}\text { L curve } \\
{[\mathrm{m}]}\end{array}$ & $\begin{array}{c}\text { Radius }^{1} \\
{[\mathrm{~m}]}\end{array}$ & $\begin{array}{c}\text { Cant }^{1} \\
{[\mathrm{~m}]}\end{array}$ \\
\hline $\mathbf{1}$ & 1000 & 63 & 500 & 600 & 0.075 \\
\hline $\mathbf{2}$ & 167 & 71 & 400 & -585 & -0.085 \\
\hline $\mathbf{3}$ & 614 & 71 & 700 & 585 & 0.085 \\
\hline $\mathbf{4}$ & 1125 & 71 & 900 & -585 & -0.085 \\
\hline $\mathbf{5}$ & 201 & 63 & 400 & 585 & 0.075 \\
\hline $\mathbf{6}$ & 809 & 63 & 300 & -575 & -0.075 \\
\hline $\mathbf{7}$ & 170 & 63 & 400 & 570 & 0.075 \\
\hline $\mathbf{8}$ & 863 & 71 & 500 & -575 & -0.085 \\
\hline $\mathbf{9}$ & 137 & 55 & 800 & -575 & -0.065 \\
\hline $\mathbf{1 0}$ & 225 & 46 & 600 & 595 & 0.055 \\
\hline
\end{tabular}

Note ${ }^{1}$ : Positive values used for right-handed curves and negative values for left-handed curves.

TABLE 10 RM LAYOUT SECTIONS

\begin{tabular}{|c|c|c|c|c|c|}
\hline \multicolumn{7}{|c|}{\begin{tabular}{c} 
RS track layout \\
\hline$\#$
\end{tabular}} & $\begin{array}{c}\text { L straight } \\
{[\mathrm{m}]}\end{array}$ & $\begin{array}{c}\mathrm{Ltransition} \\
{[\mathrm{m}]}\end{array}$ & $\begin{array}{c}\mathrm{L} \text { curve } \\
{[\mathrm{m}]}\end{array}$ & $\begin{array}{c}\text { Radius }^{1} \\
{[\mathrm{~m}]}\end{array}$ & $\begin{array}{c}\text { Cant }^{1} \\
{[\mathrm{~m}]}\end{array}$ \\
\hline $\mathbf{1}$ & 700 & 85 & 400 & 290 & 0.080 \\
\hline $\mathbf{2}$ & 500 & 100 & 200 & -300 & -0.080 \\
\hline $\mathbf{3}$ & 400 & 100 & 100 & 300 & 0.080 \\
\hline $\mathbf{4}$ & 550 & 75 & 200 & -300 & -0.080 \\
\hline $\mathbf{5}$ & 450 & 77 & 100 & 350 & 0.050 \\
\hline $\mathbf{6}$ & 400 & 95 & 300 & -315 & -0.050 \\
\hline $\mathbf{7}$ & 470 & 109 & 400 & -300 & -0.056 \\
\hline $\mathbf{8}$ & 685 & 110 & 300 & 310 & 0.050 \\
\hline $\mathbf{9}$ & 600 & 117 & 170 & 375 & 0.020 \\
\hline $\mathbf{1 0}$ & 500 & 114 & 150 & -350 & -0.060 \\
\hline
\end{tabular}

Note ${ }^{(1}$ : Positive values used for right-handed curves and negative values for left-handed curves.

TABLE 11 RS LAYOUT SECTIONS 
The specifications of the standard EN-14363 were also followed in the definition of some track defects, such as alignment and longitudinal level. To this end, their power spectral densities (PSD) were used, $\mathrm{S}(\Omega)$, where $\Omega$ is the space frequency in $\mathrm{rad} / \mathrm{m}$ :

$$
S(\Omega)=\frac{A \cdot \Omega_{C}^{2}}{\left(\Omega^{2}+\Omega_{R}^{2}\right) \cdot\left(\Omega^{2}+\Omega_{C}^{2}\right)}
$$

In this expression, the coefficients $A, \Omega_{\mathrm{R}}$ and $\Omega_{\mathrm{C}}$ should be experimentally obtained from real measurements of the track irregularities in a given track. In most of the references consulted (29), (33), (12), the values of $\Omega_{\mathrm{R}}$ and $\Omega_{\mathrm{C}}$ remain constant, and take the following values: $\Omega_{\mathrm{R}}=0.0206 \mathrm{rad} / \mathrm{m}$ and $\Omega_{\mathrm{C}}=0.8246 \mathrm{rad} / \mathrm{m}$.

Working with these values for such coefficients, the value of $A$, which is related with the amplitude of the track defects, was modified to obtain track irregularities with the standard deviation stated in the standard EN-14363 for Q1 level. In this way, the values shown in Table 12 were obtained.

\begin{tabular}{|c|c|c|}
\cline { 2 - 3 } \multicolumn{1}{c|}{} & \multicolumn{2}{c|}{ A [m-rad] } \\
\cline { 2 - 3 } \multicolumn{1}{c|}{} & Alignment & Level \\
\hline RL model & $3.134 \cdot 10^{-7}$ & $7.284 \cdot 10^{-7}$ \\
\hline RM \& RS models & $7.403 \cdot 10^{-7}$ & $15.506 \cdot 10^{-7}$ \\
\hline TABLE 12 POWER SPECTRAL DENSITY: COEFFICIENTS
\end{tabular}

To reconstruct the space excitation from the frequency function, only the wavelengths between 3 and $25 \mathrm{~m}$ were considered, this being the wavelength band considered in the standard for speeds up to $200 \mathrm{~km} / \mathrm{h}$, which is the maximum speed used in this study (see Table 15). For higher speeds, track geometry deviations with higher wavelengths should be considered.

\subsection{COUPLING OF VEHICLE AND TRACK MODELS}

Vehicle and track models were coupled through the wheel-rail contact properties, defined by the Hertz theory for the normal forces, and by the Kalker's simplified theory for the tangential forces.

In the reference model, the $\mathrm{S} 1002$ wheel profile and the UIC-60 rail profile, widely used in Europe, were included.

A value of 0.4 was chosen for the wheel-rail friction coefficient, common for dry tracks.

To consider the track elasticity in the model, track pieces were included under each wheelset. Each piece of track is directly supported by a pair of spring-damper elements (Figure 3) working in both vertical and lateral directions. The lower end of such springs follows the longitudinal movement of a given wheelset, so that these pieces of track move also along the track, following one wheelset each. This way, loads from the wheels are transferred to the corresponding track piece through Hertzian springs and the wheel normal force is transferred to the track through the vertical springs. 


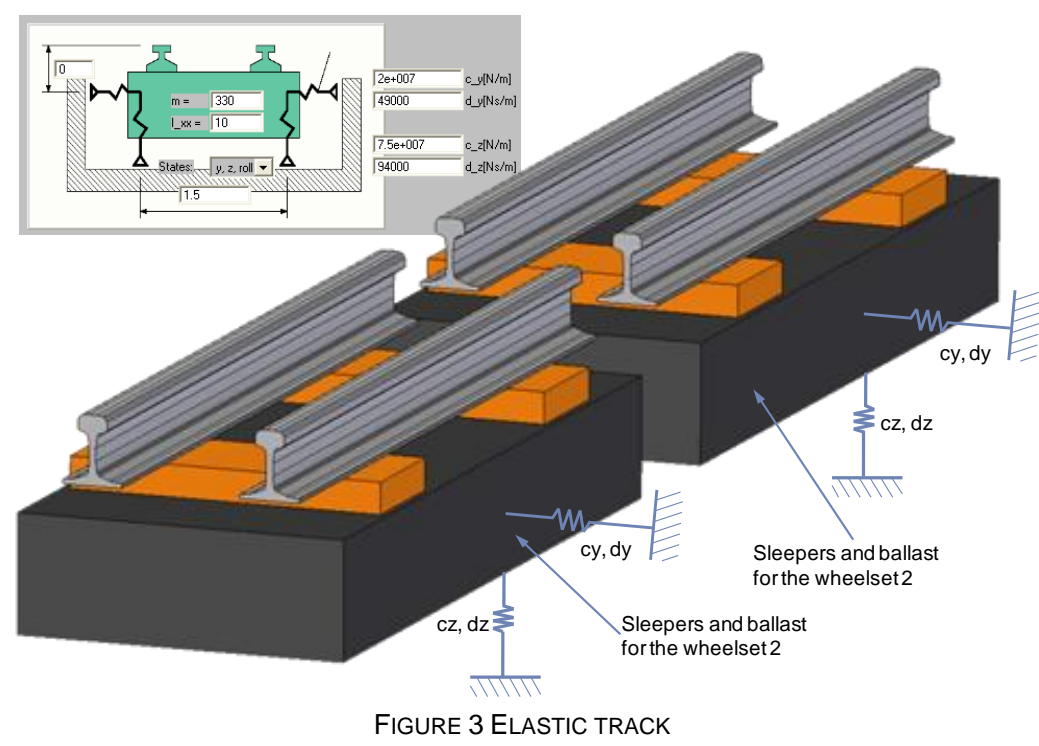

The inertial properties of each piece of track were obtained by adding to the sleeper mass that of two pieces of rail with the same length as the space between two adjacent sleepers. The result of this operation is a mass of $330 \mathrm{~kg}$. The springs stiffness and damping were taken from reference (34):

- lateral stiffness: $c y=2.0 \cdot 10^{7} \mathrm{~N} / \mathrm{m}$

- vertical stiffness: $c z=7.5 \cdot 10^{7} \mathrm{~N} / \mathrm{m}$

- lateral damping: $\mathrm{dy}=4.9 \cdot 10^{4} \mathrm{~N} \cdot \mathrm{s} / \mathrm{m}$

- vertical damping: $\mathrm{dz}=9.4 \cdot 10^{4} \mathrm{~N} \cdot \mathrm{s} / \mathrm{m}$

\subsection{OPERATING CONDITIONS}

After finishing the model, the operating conditions were set. Following the specifications of the standard EN-14363, track sections with large radius curves should be run through at speeds a $10 \%$ higher than the maximum operating speed, this being $160 \mathrm{~km} / \mathrm{h}$ for the reference vehicle. As for the running speeds for track sections with smaller radius curves, they should be calculated in terms of the cant deficiency. Table 13 gathers the speeds used in the models for each of the three track layouts.

\begin{tabular}{|cccc|}
\hline $\begin{array}{c}\text { Track } \\
\text { layout }\end{array}$ & $\mathrm{R}_{\min }[\mathrm{m}]$ & $\mathrm{R}_{\max }[\mathrm{m}]$ & $\mathrm{V}_{\max }[\mathrm{km} / \mathrm{h}]$ \\
\hline $\mathbf{R L}$ & 1620 & 1950 & 175 \\
\hline $\mathbf{R M}$ & 570 & 600 & 105 \\
\hline $\mathbf{R S}$ & 290 & 375 & 75 \\
\hline & TABLE 13 CURVE RADII AND RUNNING SPEEDS
\end{tabular}

\section{INITIAL CONDITIONS FOR THE SENSITIVITY ANALYSIS}

Before starting the actual sensitivity analysis, the speeds to be used were determined. The speed range was chosen with an upper end closer to the derailment conditions. However, the maximum speeds obtained for each track layout, RS, RM and RL, were quite different. Having in mind that the cant deficiency relates the running speed and the curve radius, the results obtained for the three track layouts for a given cant deficiency could be comparable and could be represented in a same graph. As an example, Figure 4 shows, for the three track layouts, the results obtained for the Nadal index at speeds lower than the cited maximum speeds. The left graphs represent these results as a function of the speed, and the right graphs as a function of the cant deficiency. 

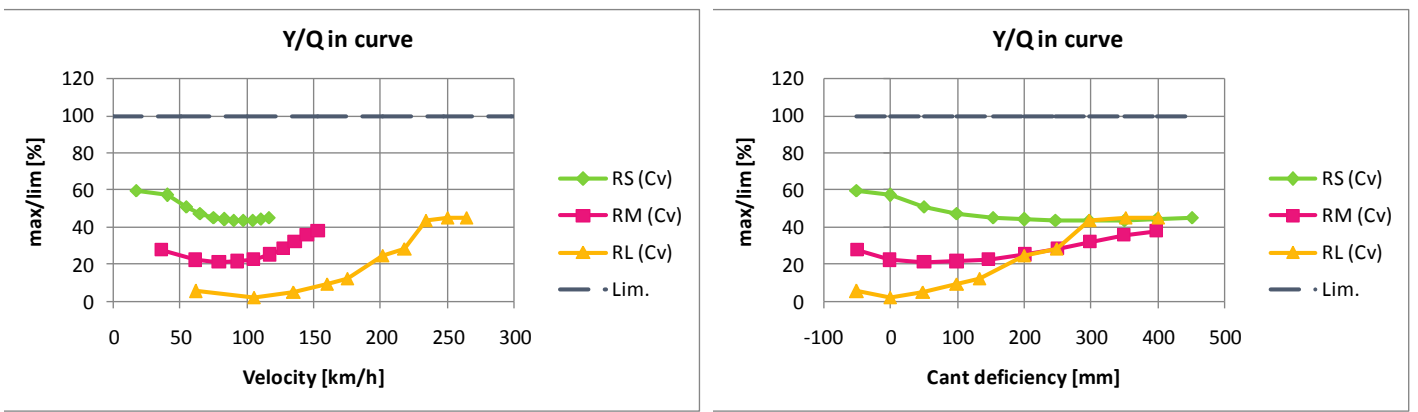

FIGURE 4 SUM OF GUIDING FORCES AND NADAL INDEX AS A FUNCTION OF SPEED (LEFT) AND CANT DEFICIENCY (RIGHT)

As can be seen, comparisons between the results of the different layouts are easier when they are represented as a function of the cant deficiency. Therefore, it was decided to define a common cant deficiency range, valid for the three track layouts. To this end, a set of cant deficiency values were chosen, uniformly distributed between -50 and $500 \mathrm{~mm}$, with $50 \mathrm{~mm}$ intervals. Then, the running speeds needed to reach these values were computed for the three track models available.

Figure 5 shows the final running speeds, V, used for each track layout to obtain the desired cant deficiencies, I, using both the radii and cants defined in Table 9, Table 10 and Table 11, respectively. The reference speeds were highlighted in bold, and triangular markers were used for the $R L$ track layout, square markers for the RM track layout and diamond-shape markers for the RS track layout.

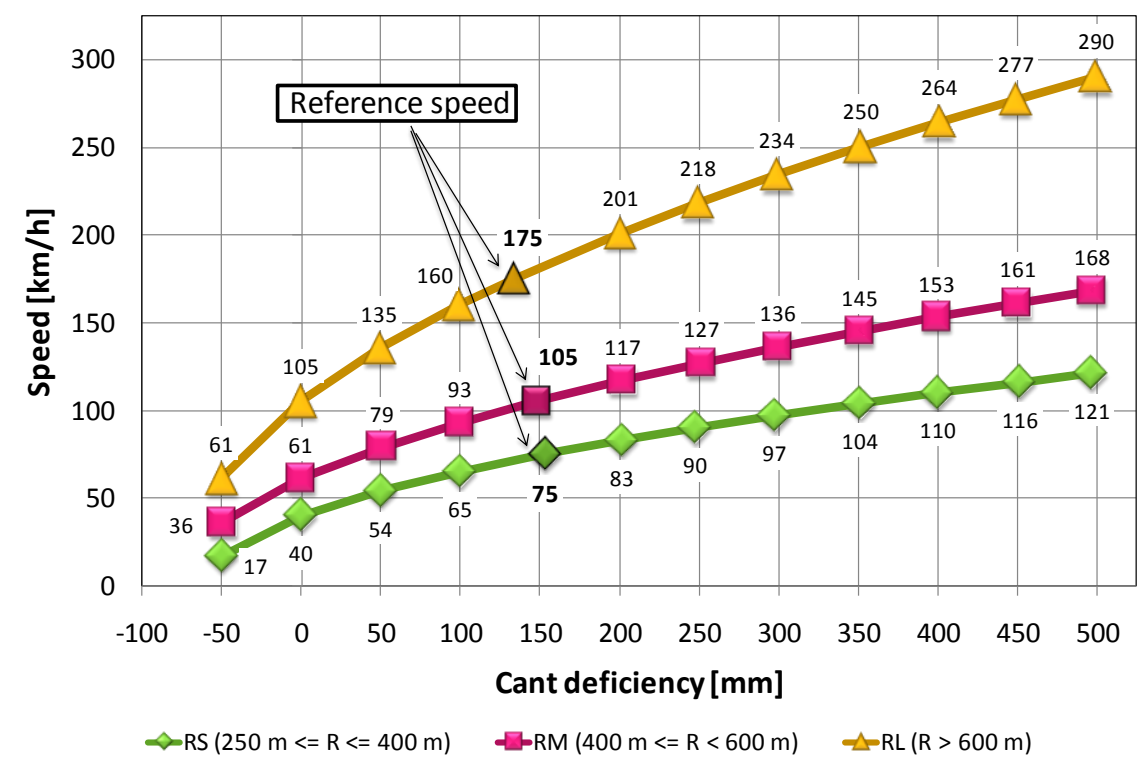

FIGURE 5 RUNNING SPEED VS. CANT DEFICIENCY

The dynamics of the reference vehicle were simulated for all these speeds, starting with the lower speed and progressively increasing it until it was detected that at least one wheel completely left the track, this indicating a derailment by excessive speed. This way, the minimum derailment speeds for each track model were identified (Table 14). 


\begin{tabular}{|l|c|c|c|}
\hline $\begin{array}{c}\text { Track } \\
\text { layout }\end{array}$ & $\begin{array}{c}\text { V } \\
{[\mathrm{km} / \mathrm{h}]}\end{array}$ & $\begin{array}{c}\text { Cant deficiency } \\
{[\mathrm{mm}]}\end{array}$ & $\begin{array}{c}\text { Vehicle } \\
\text { derails }\end{array}$ \\
\hline \multirow{2}{*}{ RS } & 116 & 452 & No \\
\hline \multirow{2}{*}{ RM } & 121 & 497 & Yes \\
\hline \multirow{2}{*}{ RL } & 153 & 399 & No \\
\hline & 161 & 450 & Yes \\
\hline & 264 & 401 & No \\
\hline
\end{tabular}

The instability critical speed was also identified for the track layout $R \mathrm{~L}$. As an example, Figure 6 shows the results obtained for RS, RM and RL track layouts for the sum of the guiding forces of the wheelset, which is related with instability, as a function of the cant deficiency considered in each simulation.

It would be noted that, as the third graph shows the results obtained in straight track sections, the x-axis should represent the speed instead of the cant deficiency, which has no sense in straight track. However, as previously said, the results in curved track can be better compared if they are represented as a function of the cant deficiency. By extension, this criterion was also applied for the results obtained for the straight track sections of a given simulation, using the same cant deficiency used in the curved track sections. This way, results in straight track sections can easily be identified with their related results in curved and transition track sections.

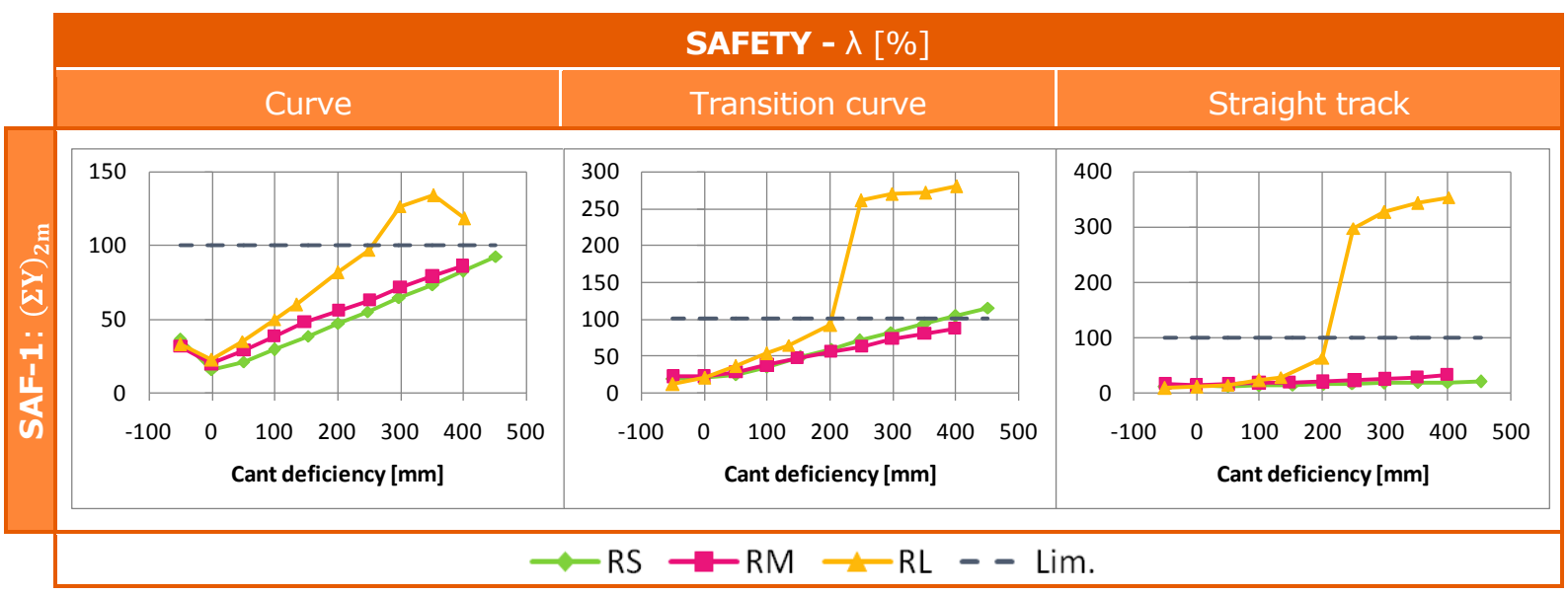

FIGURE 6 RESULTS FOR THE SPEED VARIATION: SAFETY

These graphics show an abrupt jump in the results obtained for straight track and transition curves on curves of large radius, between cant deficiencies of 200 and $250 \mathrm{~mm}$ or, which is the same thing, between speeds of 201 and $218 \mathrm{~km} / \mathrm{h}$. This indicates that, between these speeds, the reference vehicle passes from a good stable behaviour to a clear unstable behaviour.

After discarding those results with speeds over the critical speed and over the aforementioned derailment speed, the variability of the results obtained for the remaining speeds were analyzed. It was found that speed variation significantly affects the vehicle dynamics. So, the subsequent sensitivity analysis needed to be performed, not only for the reference speed of each track layout, but also for other speeds above and below the reference speed.

For each track layout, the speeds to be used in the sensitivity study were chosen from those shown in Figure 5. For the RL track, the maximum speed, Vmax, was chosen just below the instability critical speed. The minimum speed, Vmin, was chosen so that the cant deficiency for the reference speed (Vref) would lie at the midpoint between the cant 
deficiencies for the extreme speeds Vmin and Vmax. The speed variation ranges for the track models RM and RS were defined so that they would have the same cant deficiency range as the first track model, RL. The speed ranges thus obtained (Table 15) were subsequently used in the sensitivity analysis.

\begin{tabular}{|c|c|c|l|}
\hline $\begin{array}{c}\text { Track } \\
\text { layout }\end{array}$ & $\begin{array}{c}\text { Cant deficiency } \\
{[\mathrm{mm}]}\end{array}$ & $\begin{array}{c}\mathrm{V} \\
{[\mathrm{km} / \mathrm{h}]}\end{array}$ & \multicolumn{1}{|c|}{ Observations } \\
\hline \multirow{3}{*}{ RS } & 100 & 65 & Lower end \\
\hline \multirow{3}{*}{ RM } & 153 & 75 & Reference speed \\
\hline \multirow{3}{*}{ RL } & 201 & 83 & Upper end \\
\hline & 100 & 93 & Lower end \\
\hline & 148 & 105 & Reference speed \\
\hline & 202 & 117 & Upper end \\
\hline & 99 & 160 & Lower end \\
\hline \multirow{3}{*}{ TABLE 15 RUNNING SPEEDS FOR THE SENSITIVITY STUDY } \\
\hline
\end{tabular}

As can be seen, the three cant deficiencies considered for each track layout are, approximately, of 100, 150 and $200 \mathrm{~mm}$.

\section{DEFINITION OF SCENARIOS FOR THE SENSITIVITY ANALYSIS}

To perform the sensitivity analysis, the vehicle dynamics were simulated in different scenarios, which were built taking the vehicle reference model as starting point.

The first step in the definition of these scenarios was to modify independently, one at a time, the value of each of the parameters to be analyzed. Particularly, variations on the following parameters of the main bodies of the vehicle were performed:

- Carbody: mass (M), moments of inertia (Ixx, lyy, Izz), and height of the centre of gravity (cdg_z);

- Bogie: mass (M), moments of inertia (Ixx, lyy, Izz), and height of the centre of gravity (cdg_z);

- Wheelset: mass (M) and moments of inertia (Ixx, Izz).

Apart from the reference value, two additional values were considered for each parameter: a higher value and a lower value, corresponding to the percentiles 10 and 90 of the data set stored in the RVDynDB database (7), as indicated in Table 16. 


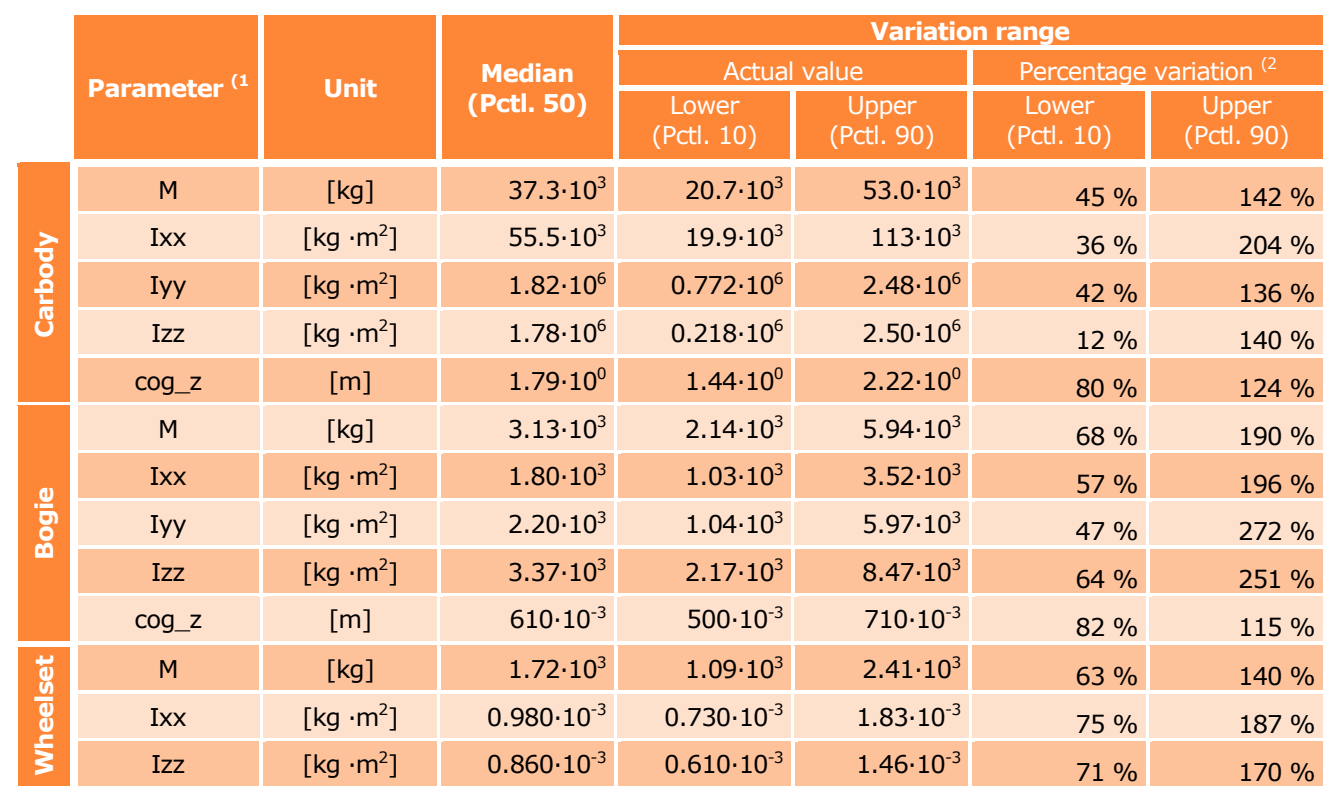

Note ${ }^{(1}:$ M: mass; Ijj: moment of inertia around the $j$ axis; $\operatorname{cog} z$ z: vertical position of the centre of gravity; Note (2: Relative variation of lower and upper ends as a percentage of the median value, being Pctl. $50=100 \%$

TABLE 16 MEDIAN AND VARIATION RANGE OF BODIES PARAMETERS

From Table 16, it can be observed that some parameters, as the carbody Ixx and Izz, present wide variation ranges. In addition, some parameters, as the carbody Izz, present even skewed variation ranges. Although both the amplitude and asymmetry of the variation ranges were taken into account when assessing the influence of each parameter, they could affect the sensitivity study, probably making the results somewhat skewed towards parameters that naturally have a wide variation. However, it should be remembered that the present study intends to obtain qualitative, but not quantitative, results.

Several operating conditions were considered for each of these values. Particularly, each vehicle model was combined with the track layouts $R S, R M$ and $R L$, all of them with track quality Q1. In turn, each track layout was run through at the running speeds Vmin, Vref and Vmax.

12 different scenarios were considered: 5 to analyze the influence of the inertial properties of the carbody, 5 to analyze the inertial properties of the bogie and 2 to analyze the inertial properties of the wheelset. Once the models were ready, they were simulated, with a total of 216 simulations (12 parameters - 2 variations - 3 speeds $\cdot 3$ track layouts), apart from the 3 simulations needed to analyze the reference case.

\section{POST-PROCESSING METHODOLOGY}

To make the comparison between the results of different simulations easier, the postprocessing methodology was systematized, reducing all the results of each simulation to a small set of indexes. To this end, the indications of the standard EN-14363 were again followed. This standard proposes a statistical evaluation which allows the assessment of the vehicle dynamics from the safety, track fatigue and ride quality points of view.

The assessment quantities related with safety are the sum of the guiding forces of the wheelsets, the Nadal index, the lateral acceleration of the bogies and the lateral acceleration of the carbody; those related with track fatigue are the vertical and lateral wheel forces; and those related with ride quality are the lateral and vertical carbody accelerations. As a whole, 5 assessment quantities were considered to evaluate running safety, 3 for track fatigue and another 5 for ride quality (see Table 17) 


\begin{tabular}{|c|c|c|c|}
\hline & Index & Assessment quantity & Symbol \\
\hline \multirow{5}{*}{$\begin{array}{l}\stackrel{\overrightarrow{0}}{\mathbb{N}} \\
\text { ñ }\end{array}$} & SAF-1 & Sum of wheelset guiding forces & $(\Sigma \mathrm{Y})_{2 \mathrm{~m}}$ \\
\hline & SAF-2 & Ratio of guiding force and wheel load & $(\mathrm{Y} / \mathrm{Q})$ \\
\hline & SAF-3 & Lateral acceleration of the bogie frame & $\ddot{y}_{s}^{+}$ \\
\hline & SAF-4 & Lateral acceleration of the carbody & $\ddot{y}_{s}^{*}$ \\
\hline & SAF-5 & Root mean square of the sum of wheelset guiding forces & $s \Sigma Y$ \\
\hline \multirow{3}{*}{ 兽 } & FAT-1 & Vertical wheel load & $Q$ \\
\hline & FAT-2 & Quasi-static lateral wheel force & $Y_{q s t}$ \\
\hline & FAT-3 & Quasi-static vertical wheel force & $Q_{q s t}$ \\
\hline \multirow{5}{*}{$\begin{array}{l}\frac{z}{0} \\
\frac{0}{0} \\
\frac{0}{0} \\
\frac{0}{\alpha}\end{array}$} & COM-1 & Lateral acceleration of the carbody & $\ddot{y}_{q}^{*}$ \\
\hline & COM-2 & Vertical acceleration of the carbody & $\ddot{z}_{q}^{*}$ \\
\hline & COM-3 & Root mean square of lateral acceleration of the carbody & $s \ddot{y}_{q}^{*}$ \\
\hline & COM-4 & Root mean square of vertical acceleration of the carbody & $\mathrm{s} \ddot{z}_{q}^{*}$ \\
\hline & COM-5 & Quasi-static lateral acceleration of the carbody & $\ddot{y}_{q s t}^{*}$ \\
\hline
\end{tabular}

TABLE 17 ASSESSMENT QUANTITIES FOR SAFETY, TRACK FATIGUE AND RIDE QUALITY

The simulation results for each assessment quantity were post-processed following the indications of the standard EN-14363, in order to calculate their maximum estimated values.

The standard also provides a limit value for each of these assessment quantities, considering that the vehicle dynamic behaviour is suitable if the maximum estimated value for each assessment quantity is less than its related limit value. Of the five criteria used to evaluate running safety, the first one is related with track shifting (10), in accordance with Prud'homme's criteria (35); the second with flange climbing derailment, following Nadal's criterion; the third one with bogie instability (36) and (37); and the fourth and fifth with vehicle instability (10). The criteria used to evaluate track fatigue are related to the lateral and vertical wheel loads, and those used to evaluate ride quality are related to carbody accelerations.

\section{INDIVIDUAL RESULTS OF THE SENSITIVITY ANALYSIS}

After finishing the models and performing the appropriate simulations, the next step is to process the results obtained, following the indications of the standard EN-14363. The influence of a given parameter can then be determined by comparing each assessment index for all the simulations related to that parameter. These influences were independently evaluated for the different assessment quantities related to safety, track fatigue and ride quality studies.

\subsection{DESCRIPTION OF THE GRAPHICS AND TABLES USED}

\subsubsection{Result graphs}

When presenting the results, all the safety evaluation indexes (SAF) obtained when modifying a given parameter are grouped, as well as all the track fatigue (FAT) indexes and the ride quality (COM) indexes.

To make comparisons easier, a $\lambda$ ratio is computed for each evaluation index. $\lambda$ represents the ratio between the maximum estimated value of the assessment quantity being analyzed, and its related limit value. It is expressed as a percentage, so that values under $100 \%$ represent standard-compliant situations, while those over $100 \%$ represent non-compliant ones. 
A different graph was used for each evaluation criterion (SAF-1/5, FAT-1/3 or COM-1/5), and for each type of track section (curve, transition curve or straight track). In each graph, the results obtained in the simulations with track models RS (line with diamond-shape markers), RM (line with square markers) and RL (line with triangular markers) are shown together.

The $y$-axis shows the $\lambda$ ratio, while the different scenarios used in the simulations are represented along the $x$-axis, by combining each running speed (Vmin/Vref/Vmax) with the three values assigned to the parameter being considered (P10/P50/P90).

As an example, Figure 7 shows the results obtained for the variations performed on the carbody mass, mc, for the safety indexes SAF-1 and SAF-2, respectively related with the sum of guiding forces, $(\Sigma \mathrm{Y})_{2 \mathrm{~m}}$, and with the Nadal index, $(\mathrm{Y} / \mathrm{Q})$.

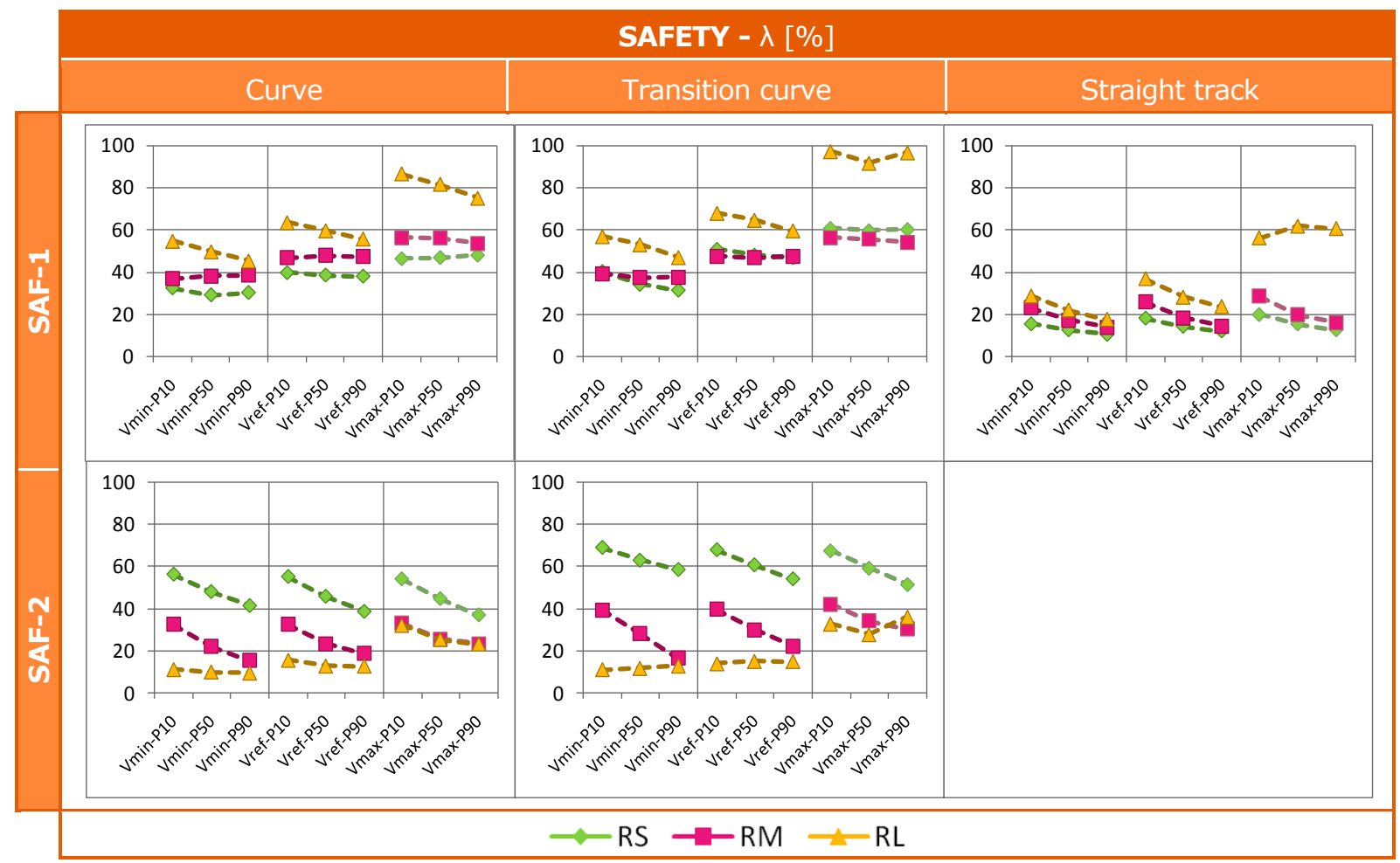

FIGURE 7 GRAPHICAL RESULTS OF THE VARIATIONS OF THE CARBODY MASS: SAFETY

Note that each point in the graph represents the result obtained in a different simulation. Therefore, the lines connecting similar cases for percentiles 10,50 y 90 have no physical meaning, though they were represented to provide a graphical notion of the influence related to the parameter variation.

These graphs were represented to facilitate the interpretation of the influences related to each parameter. However, due to the great amount of results obtained, they will no longer be used in this paper. Instead of analyzing the previous graphs, one at a time, it was preferred to compact this information in several tables, from which a clearer and more evident conclusion could be obtained.

\subsubsection{Table of influences}

To assess the influence of the modified parameter, an influence indicator was computed, combining the $\lambda$ ratios obtained for either the percentiles P10 or P90 and for the percentile P50 of the parameter being modified:

$$
I n f_{n}=\frac{\lambda_{n}-\lambda_{50}}{(P n-P 50) / P 50}, \quad n=10,90
$$


Note that, being $\lambda$ the ratio between the maximum estimated value of the assessment quantity being analyzed and its related limit value, the influence indicator represents the ratio between the relative variation of the output and the relative variation of the modified parameter. Its denominator would be 1 if the modified parameter would increase a $100 \%$ from P50 to P90, or -1 if it would decrease a $100 \%$ from P50 to P10. Therefore, if the variation of the output is supposed to be linear, an influence indicator of $r \%$ means that the maximum estimated value of the assessment quantity being analyzed increases/decreases an $r \%$ of its related limit value when the modified parameter increases/decreases a $100 \%$. According to this interpretation, 5 different levels were set for the influence of a given parameter: low $(|\operatorname{lnf}|<10 \%)$; moderate $(10 \% \leq|\operatorname{lnf}|<25 \%)$; noticeable $(25 \% \leq|\operatorname{lnf}|<50 \%)$; high $(50 \% \leq|\operatorname{lnf}|<75 \%)$ and very high $(|\operatorname{lnf}| \geq 75 \%)$.

\subsubsection{Table of global influences}

For each evaluation index, the influence indicators obtained for percentiles P10 and P90 with the same track layout, the same speed and the same type of track section were compared to obtain the highest influence. This was computed as the influence indicator with the highest absolute value:

$$
\widehat{\operatorname{Inf}}= \begin{cases}\operatorname{Inf} f_{10}, & \text { if }\left|\operatorname{Inf} f_{10}\right| \geq\left|\operatorname{Inf} f_{90}\right| \\ \operatorname{Inf} f_{90}, & \text { if }\left|\operatorname{Inf_{90}}\right| \geq\left|\operatorname{Inf} f_{10}\right|\end{cases}
$$

To further ease the appraisal of the simulation results for each evaluation index, the highest influences were grouped by type of track section (Cv, Tr, St) (see Table 18). They were also grouped by track layout (RS, RM $\circ \mathrm{RL}$ ) and by speed (Vmin, Vref and Vmax). Then, the global influence was calculated as the highest absolute value obtained inside each group.

The global influences were put together in a table (see Table 19), where columns 3-5 show the global influence found for each type of track section: curve, $\mathrm{Cv}$, transition curve, $\mathrm{Tr}$, and straight track, St; columns 6-8 show the global influence found for each track layout: $\mathrm{RS}, \mathrm{RM}$ and RL; and columns 9-11 show the global influence found for each speed category: Vmin, Vref and Vmax. The last column shows the highest global influence obtained in all these categories. This table allows to quickly determine which kind of dynamic behaviour leads to the most critical situations. The least critical results (below 10\%) were identified with an empty circle, $\bigcirc$, the most critical (over $75 \%$ ) with a full black circle, - and the intermediate ones with partially-filled circles: for influences between $10 \%$ and $25 \%$, for influences between $25 \%$ and $50 \%$, and -50 for influences between 50 and $75 \%$.

\subsubsection{Numerical example}

As an example, for the variations performed on the carbody mass, the mass takes the values: $\mathrm{P} 10=20.96 \mathrm{t}$; $\mathrm{P} 50=37.33 \mathrm{t}$; P90 $=53.03 \mathrm{t}$. For the evaluation index SAF-1, the corresponding $\lambda$ ratios obtained for the simulations performed for RS track layout at Vmin in curved track sections, $C v$, are: $\lambda_{10}=32.3 \% ; \lambda_{50}=29.2 \% ; \lambda_{90}=30.2 \%$. From these values, the related influence indicators result in: $\operatorname{lnf}_{10}=3.1 \% /(-0.45)=-6.95 \%$ and $\operatorname{Inf}_{90}=1.0 \% / 0.42=2.38 \%$, the highest influence being $-6.95 \%$. This value is collected in the top-left cells of the three blocks of Table 18.

Table 18 shows the highest influences computed for the evaluation index SAF-1 when modifying the carbody mass. The left, central and right blocks respectively show the highest influences grouped by type of track section (Cv, Tr, St), by track layout (RS, RM, RL) and by speed (Vmin, Vref, Vmax). The value with highest absolute value of each column was highlighted in bold. 


\begin{tabular}{|c|c|c|c|c|c|c|c|c|c|c|c|}
\hline & (Cv) & (Tr) & (St) & & RS & RM & RL & & Vmin & Vref & $V \max$ \\
\hline RS-Vmin & -6.95 & -13.01 & -6.50 & Cv-Vmin & -6.95 & 3.36 & -11.21 & RS-Cv & -6.95 & -3.14 & 2.85 \\
\hline RS-Vref & -3.14 & -6.50 & -8.97 & Cv-Vref & -3.14 & 2.92 & -9.99 & RS-Tr & -13.01 & -6.50 & -2.47 \\
\hline $\mathrm{RS}-\mathrm{V} \max$ & 2.85 & -2.47 & -10.32 & Cv-Vmax & 2.85 & -5.95 & -14.98 & RS-St & -6.50 & -8.97 & -10.32 \\
\hline $\mathrm{RM}-V_{\min }$ & 3.36 & -4.48 & -13.01 & Tr-Vmin & -13.01 & -4.48 & -14.51 & RM-Cv & 3.36 & 2.92 & -5.95 \\
\hline RM-Vref & 2.92 & 2.38 & -16.82 & Tr-Vref & -6.50 & 2.38 & -12.60 & RM-Tr & -4.48 & 2.38 & -3.57 \\
\hline RM-Vmax & -5.95 & -3.57 & -19.51 & Tr-Vmax & -2.47 & -3.57 & -12.33 & RM-St & -13.01 & -16.82 & -19.51 \\
\hline $\mathrm{RL}-\mathrm{V}_{\min }$ & -11.21 & -14.51 & -15.92 & St-Vmin & -6.50 & -13.01 & -15.92 & RL-CV & -11.21 & -9.99 & -14.98 \\
\hline RL-Vref & -9.99 & -12.60 & -18.84 & St-Vref & -8.97 & -16.82 & -18.84 & RL-Tr & -14.51 & -12.60 & -12.33 \\
\hline RL-Vmax & -14.98 & -12.33 & 13.23 & St-Vmax & -10.32 & -19.51 & 13.23 & RL-St & -15.92 & -18.84 & 13.23 \\
\hline
\end{tabular}

Finally, Table 19 shows the global influence for the variations in the carbody mass, mc, for the five safety criteria. Note that the values gathered in the second row are the highlighted values of Table 18 rounded to the nearest integer.

\begin{tabular}{|c|c|c|c|c|c|c|c|c|c|c|c|c|}
\hline \multirow{2}{*}{ Index } & \multirow{2}{*}{$\begin{array}{l}\text { Assess. } \\
\text { quantity }\end{array}$} & \multicolumn{4}{|c|}{ Type of track section } & \multicolumn{3}{|c|}{ Track layout } & \multicolumn{3}{|c|}{ Speed } & \multirow{2}{*}{ MAX } \\
\hline & & & $\mathrm{Cv}$ & $\operatorname{Tr}$ & St & RS & RM & RL & Vmin & Vref & Vmax & \\
\hline$A F-1$ & $(\Sigma Y)_{2 m}$ & () & $-15 \odot$ & $-15 \odot$ & $-20 c$ & -130 & -200 & $-19 \bullet$ & $-16 \odot$ & $-19 \odot$ & -200 & -20 \\
\hline SAF-2 & $Y / Q)_{2 m}$ & 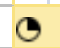 & -240 & -28 & c & -220 & $-28 C$ & 200 & $-28 c$ & $-22 \theta$ & $-22 థ$ & -28 \\
\hline SAF-3 & $\ddot{v}^{+}$ & () & $16 \bullet$ & $56 \bullet$ & 650 & 10 & 20 & $65 \div$ & $-12 \odot$ & $16 \bullet$ & 650 & 65 \\
\hline SAF-4 & $\ddot{\ddot{*}}$ & () & -220 & $-8 \odot$ & $-20 c$ & $-16 \odot$ & $-20 \odot$ & -220 & $-18 c$ & $-16 \odot$ & -220 & -22 \\
\hline SAF-5 & $s \sum Y$ & ) & -130 & $34 \bullet$ & 590 & -10 & -10 & 590 & $13 c$ & $-15 \bullet$ & $59 \bullet$ & 59 \\
\hline
\end{tabular}

Variation range (P10; P90)trom $55 \%$ to $142 \%$ of the reference value (P50).

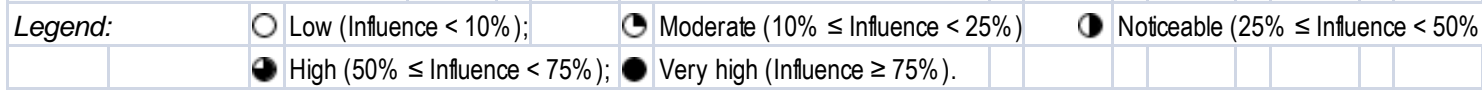

TABLE 19 TABLE OF GLOBAL INFLUENCES: MASS OF THE CARBODY

Whether the global influences were classified by type of track section, by track layout or by speed, the highest global influence found is always the same (65\% in this example). In this way, it is easy to identify which is the type of track section, the track layout or even the vehicle speed that show the highest global influence. On the other hand, by looking at the values in the last column, it is also possible to identify which evaluation index provides the highest global influence.

In the following paragraphs, the global influences obtained when comparing the results of the different simulations performed are presented. Hereafter, for simplicity, global influences will be called just influences.

\subsection{INFLUENCE OF THE INERTIAL PROPERTIES OF THE CARBODY}

The following tables show the influence obtained when analyzing the following inertial properties of the carbody:

- Mass of the carbody, mc (Table 20)

- Moment of inertia of the carbody around the $x$ axis, IXc (Table 21)

- Moment of inertia of the carbody around the y axis, IYc (Table 22)

- Moment of inertia of the carbody around the $z$ axis, IZc (Table 23)

- Height of the centre of gravity of the carbody, ZGc (Table 24) 


\begin{tabular}{|c|c|c|c|c|c|c|c|c|c|c|c|c|}
\hline \multirow{2}{*}{ Index } & \multirow{2}{*}{$\begin{array}{l}\text { Assess. } \\
\text { quantity }\end{array}$} & \multicolumn{4}{|c|}{ Type of track section } & \multicolumn{3}{|c|}{ Track layout } & \multicolumn{3}{|c|}{ Speed } & \multirow{2}{*}{ MAX } \\
\hline & & \multicolumn{2}{|c|}{ Cv } & \multirow{2}{*}{ Tr -150} & & \multirow{2}{*}{$\begin{array}{l}\text { RS } \\
-13 \mathrm{C}\end{array}$} & RM & RL & Vmin & \multirow{2}{*}{ Vref } & Vmax & \\
\hline AF-1 & $(\Sigma Y)_{2 m}$ & () & $-15 \odot$ & & & & $-20 \bullet$ & $-19 c$ & $-16 \odot$ & & $-20 c$ & -20 \\
\hline AF-2 & $(Q)_{2 m}$ & c) & $-24 \oplus$ & -28 & $c$ & -220 & $-28 \mathrm{c}$ & 20 & -280 & $-22 \odot$ & $-22 \boldsymbol{\Phi}$ & 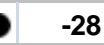 \\
\hline$F-3$ & $\ddot{y}_{s}^{+}$ & c) & $16 \bullet$ & $56 \bullet$ & $65 C$ & 10 & $2 \bullet$ & $65 \odot$ & $-12 \odot$ & $16 \bullet$ & 650 & 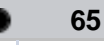 \\
\hline $\mathrm{F}-4$ & $\ddot{y}_{s}^{*}$ & () & -220 & -80 & $-20 c$ & $-16 \bullet$ & $-20 \Leftrightarrow$ & $-22 \odot$ & $-18 \odot$ & $-16 \bullet$ & $-22 \bullet$ & -22 \\
\hline$F-5$ & $\sum Y$ & - & $-13 \boldsymbol{C}$ & $34 \bullet$ & $59 C$ & -10 & $-1 \bullet$ & 596 & 130 & $-15 \bullet$ & $59 \bullet$ & 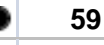 \\
\hline \multirow{2}{*}{ Index } & \multirow{2}{*}{$\begin{array}{l}\text { Assess. } \\
\text { quantity }\end{array}$} & \multicolumn{4}{|c|}{ Type of track section } & \multicolumn{3}{|c|}{ Track layout } & \multicolumn{3}{|c|}{ Speed } & MAX \\
\hline & & & Cv & $\operatorname{Tr}$ & St & RS & RM & RL & Vmin & Vref & Vmax & $\mathbf{A X}$ \\
\hline FAT-1 & $Q$ & $\bullet$ & $61 \bullet$ & 520 & 26 & $61 \bullet$ & $61 \bullet$ & $60 \oplus$ & 41 ( & $50 \bullet$ & $61 \bullet$ & \\
\hline AT-2 & $Y_{q s t}$ & () & 24 & - & - & $24 \bullet$ & 23 & - & $20 \bullet$ & 220 & $24 C$ & 24 \\
\hline AT-3 & $Q_{q s t}$ & $\bullet$ & 62 & - & - & $62 \bullet$ & 62 & - & $47 \bullet$ & $54 \bullet$ & 620 & 62 \\
\hline ex & Asse: & & Type of $t$ & track se & tion & Trac & k layout & & & Speed & & \\
\hline$=x$ & & & & $\operatorname{Tr}$ & St & RS & RM & RL & Vmin & Vref & Vmax & an \\
\hline OM-1 & 59 & c) & $-22 \bullet$ & $-16 \odot$ & $-18 C$ & $-15 \odot$ & $-18 \bullet$ & $-22 \odot$ & $-18 \odot$ & $-17 \odot$ & $-22 €$ & -22 \\
\hline M-2 & $\dddot{z}_{q}^{*}$ & c) & $-19 \bullet$ & $-16 \odot$ & $-19 c$ & $15 \odot$ & $-17 C$ & $-19 \odot$ & $-19 \bullet$ & $-17 \odot$ & $-16 C$ & -19 \\
\hline M-3 & $s \ddot{y}_{q}^{*}$ & $\bullet$ & -66 & $-43 \bullet$ & -50 & $-39 \bullet$ & -50 & -66 & -470 & $-49 \bullet$ & -66 & -66 \\
\hline DM-4 & $s \ddot{z}_{q}$ & () & -310 & $-29 \boldsymbol{C}$ & -340 & 27 ○ & $-30 \oplus$ & $-34 \oplus$ & $-34 \oplus$ & $-30 \oplus$ & $27 \boldsymbol{\oplus}$ & -34 \\
\hline OM-5 & $\ddot{y}_{q s t}^{*}$ & 0 & -1 & - & C & 00 & 00 & -10 & -10 & -10 & -10 & D \\
\hline Variatiol & on range ( & $10 ;$ & P90)from & $55 \%$ to & $142 \%$ & of the referer & nce value & e (P50). & & & & \\
\hline Legend: & & & Low (Influen & רce < $10 \%$ ); & & (5) Moderate (1 & $10 \% \leq$ Influ & ience $<25 \%$ & (1) No & loticeable (25 & $5 \% \leq$ Influen & nce $<50 \%$ \\
\hline & & - । & High $(50 \%$ & $\leq$ Influence & $<75 \%)$ & Very high (I & Influence $\geq$ & $(5 \%)$. & & & & \\
\hline & & & & TABLE $20 \mathrm{~T}$ & TOTAL VA & ARIABILITY OF & RESUL & : MASS OF & $\mathrm{BO}$ & & & \\
\hline dex & ess. & & Type of $t$ & track sect & tion & Trac & k layout & & & Speed & & \\
\hline dex & tity & & Cv & $\operatorname{Tr}$ & St & RS & RM & RL & Vmin & Vref & $V \max$ & \\
\hline F-1 & $(\Sigma Y)_{2 m}$ & 0 & -3.40 & 2.00 & $3.4 C$ & 3.30 & $3.4 \mathrm{O}$ & -3.40 & $3.4 \mathrm{O}$ & -3.10 & 3.30 & 3.4 \\
\hline $\mathrm{F}-2$ & $(Y / Q)_{2 m}$ & 0 & 1.40 & -1.4 & $c$ & 1. & $1.4 \mathrm{O}$ & -1.40 & 1. & 1.40 & $-1.4 \mathrm{O}$ & -1.4 \\
\hline$F-3$ & $\ddot{\ddot{i}}^{+}$ & 0 & -0.60 & -3.90 & $-2.3 C$ & 0.30 & 0.50 & -3.90 & -0.60 & -0.90 & -3.90 & -3.9 \\
\hline-4 & $\ddot{y}$ & 0 & -5.10 & -3.40 & $-4.0 C$ & -4.00 & -5.10 & 2.50 & -5.10 & -3.60 & -3.30 & -5.1 \\
\hline SAF-5 & $s \Sigma Y$ & 0 & -2.80 & 1.20 & $0.9 C$ & 0.00 & 0.00 & -2.80 & -0.60 & -0.50 & -2.80 & -2.8 \\
\hline & Asse: & & Type of $t$ & track sect & tion & Trac & ok layout & & & Speed & & \\
\hline & & & Cv & $\mathrm{Tr}$ & St & RS & RM & RL & Vmin & Vref & Vmax & $A x$ \\
\hline $\mathrm{T}-1$ & $Q$ & 0 & -0.30 & -0.30 & $-0.3 C$ & -0.30 & -0.20 & 0.30 & -0.30 & -0.30 & -0.30 & -0.3 \\
\hline $\mathrm{T}-2$ & $Y_{q s t}$ & 0 & 0.5 & - & - & 0.50 & 0.5 & 0 & 0.50 & $0.4 O$ & 0.50 & 0.5 \\
\hline FAT-3 & $Q_{q s t}$ & 0 & 0.0 & $\begin{array}{lll}- & -1\end{array}$ & $c$ & 0.00 & 0.0 & 0 & 0.00 & 0.00 & 0.00 & 0.0 \\
\hline Index & & & Type & track & tion & Trac & sk layout & & & Speed & & $x$ \\
\hline moex & & & Cv & $\mathrm{Tr}$ & St & RS & RM & RL & $\min$ & Vref & Vmax & \\
\hline COM-1 & $\ddot{y}_{q}^{*}$ & 0 & -4.70 & -3.10 & $-4.2 C$ & -4.20 & -4.70 & 1.90 & -4.70 & -3.40 & $-3.4 \mathrm{O}$ & -4.7 \\
\hline COM-2 & $\ddot{z}_{q}^{*}$ & 0 & -0.20 & 0.30 & $0.1 \mathrm{C}$ & -0.20 & 0.20 & 0.30 & 0.20 & 0.30 & -0.20 & 0.3 \\
\hline-3 & $s \ddot{y}_{c}$ & c & $-14.3 \odot$ & $-12.9 \odot$ & $-11.7 C$ & -11.70 & -14.30 & $5.5 \odot$ & $-14.3 \odot$ & $-11.2 \odot$ & $-11.7 \mathrm{C}$ & -14.3 \\
\hline COM-4 & $s \ddot{z}_{q}$ & 0 & 0.30 & 0.50 & $-0.2 C$ & 0.30 & 0.20 & 0.50 & 0.30 & 0.50 & 0.30 & 0.5 \\
\hline COM-5 & $\ddot{y}_{q s t}$ & 0 & 0.6 & & C & 0.20 & -0.20 & 0.60 & 0.50 & 0.60 & -0.20 & 0.6 \\
\hline Variatiol & on range (I & $10 ;$ & P90)from & $36 \%$ to & $204 \%$ & of the ref & value & (P50). & & & & \\
\hline Legend: & & 01 & Low (Influen & nce < $10 \%$ ); & & (5) Moderate (1 & $10 \% \leq \ln$ & ence $<25 \%$ ) & ( No & e $125^{\circ}$ & nfluen & $<50 \%$ \\
\hline & & $\boldsymbol{\bullet}$ & & $\leq$ Influen & $\%) ;$ & Very high & Influence & (1) & & & & \\
\hline
\end{tabular}

TABLE 21 TOTAL VARIABILITY OF RESULTS: MOMENT OF INERTIA OF THE CARBODY AROUND THE X AXIS 


\begin{tabular}{|c|c|c|c|c|c|c|c|c|c|c|c|c|c|}
\hline \multirow{2}{*}{ Index } & \multirow{2}{*}{$\begin{array}{l}\text { Assess. } \\
\text { quantity }\end{array}$} & \multicolumn{4}{|c|}{ Type of track section } & \multicolumn{4}{|c|}{ Track layout } & \multicolumn{3}{|c|}{ Speed } & \multirow{2}{*}{ MAX } \\
\hline & & & $\mathrm{cv}$ & $\mathrm{Tr}$ & St & RS & & RM & RL & Vmin & Vref & Vmax & \\
\hline AF-1 & $(\Sigma Y)_{2 m}$ & 0 & 00 & -10 & 1 & & 00 & -10 & 10 & 00 & 00 & 10 & \\
\hline AF-2 & $(Q)_{2 m}$ & 0 & -10 & -2 & - & & 00 & -20 & 10 & 10 & 00 & -20 & -2 \\
\hline $\mathrm{F}-3$ & $\ddot{\ddot{x}}^{+}$ & 0 & 00 & 10 & 1 & & 00 & 00 & 10 & 00 & 10 & 10 & 1 \\
\hline $\mathrm{F}-4$ & $\ddot{y}$ & 0 & -10 & 00 & 0 & & 0 & 00 & -10 & 00 & 00 & -10 & -1 \\
\hline $\mathrm{F}-5$ & $s \Sigma Y$ & 0 & 10 & 00 & 1 & & 00 & 00 & 10 & 00 & 10 & 10 & 1 \\
\hline \multirow{2}{*}{ Index } & \multirow{2}{*}{\multicolumn{2}{|c|}{$\begin{array}{l}\text { Assess. } \\
\text { quantity }\end{array}$}} & \multicolumn{3}{|c|}{ Type of track section } & \multicolumn{4}{|c|}{ Track layout } & \multicolumn{3}{|c|}{ Speed } & \multirow{2}{*}{ IAX } \\
\hline & & & $\mathrm{Cv}$ & $\operatorname{Tr}$ & St & RS & & RM & RL & Vmin & Vref & Vmax & \\
\hline AT-1 & $Q$ & 0 & -10 & 10 & -1 & & 00 & 10 & 00 & 10 & 10 & 10 & \\
\hline $\mathrm{T}-2$ & $Y_{\text {a }}$ & 0 & 0 & - & - & & 00 & 0 & 0 & 00 & 00 & 00 & \\
\hline AT-3 & $Q_{q s t}$ & 0 & 0 & - & - & & 00 & 0 & O & 00 & 00 & 00 & 0 \\
\hline \multirow{2}{*}{ Index } & \multirow{2}{*}{\multicolumn{2}{|c|}{$\begin{array}{l}\text { Assess. } \\
\text { quantity }\end{array}$}} & \multicolumn{3}{|c|}{ Type of track section } & \multicolumn{4}{|c|}{ Track layout } & \multicolumn{3}{|c|}{ Speed } & \multirow[b]{2}{*}{ MAX } \\
\hline & & & Cv & $\operatorname{Tr}$ & s. & RS & & RM & RL & Vmin & ef & Vmax & \\
\hline OM-1 & $\because \because *$ & 0 & -10 & 00 & 0 & & 00 & 00 & -10 & 00 & 00 & -10 & -1 \\
\hline DM-2 & $\ddot{z}_{q}^{*}$ & () & -310 & $-30 \oplus$ & -36 & & 30 & $-25 \oplus$ & $-36 c$ & 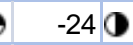 & $-33 \boldsymbol{\square}$ & -36 & -36 \\
\hline COM-3 & $s \ddot{y}_{c}^{*}$ & 0 & -10 & -10 & 1 & & 10 & -10 & -10 & 00 & -10 & -10 & -1 \\
\hline COM-4 & $s \ddot{z}_{q}^{*}$ & $\bullet$ & $-64 \bullet$ & $-68 \bullet$ & 74 & & 4 & -49 & -740 & $-45 \odot$ & -65 & $-74 \bullet$ & -74 \\
\hline COM-5 & $\ddot{y}_{q s t}^{*}$ & 0 & 0 & & - & & 00 & 00 & 00 & 00 & 00 & 00 & c \\
\hline
\end{tabular}

Variation range (P10; P90)from $42 \%$ to $136 \%$ of the reference value (P50).

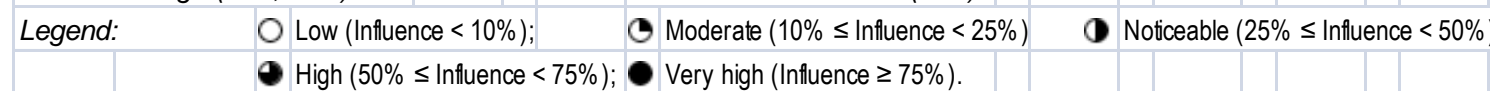

TABLE 22 TOTAL VARIABILITY OF RESULTS: MOMENT OF INERTIA OF THE CARBODY AROUND THE Y AXIS

\begin{tabular}{|c|c|c|c|c|c|c|c|c|c|c|c|c|}
\hline \multirow{2}{*}{ Index } & \multirow{2}{*}{$\begin{array}{l}\text { Assess. } \\
\text { quantity }\end{array}$} & \multicolumn{4}{|c|}{ Type of track section } & \multicolumn{3}{|c|}{ Track layout } & \multicolumn{3}{|c|}{ Speed } & \multirow{2}{*}{ MAX } \\
\hline & & & Cv & $\operatorname{Tr}$ & St & RS & RM & $\mathbf{R L}$ & Vmin & Vref & $V \max$ & \\
\hline AF-1 & $\left(\sum Y\right)_{2 m}$ & ( & -390 & -228 & -2810 & -30 & -3 & -2810 & -60 & -10 & -2810 & -281 \\
\hline SAF-2 & $Q)_{2 m}$ & () & -240 & -148 & - & -1 & 10 & $-148 \mathrm{C}$ & -30 & $-4 \bullet$ & -1480 & -148 \\
\hline SAF-3 & . & $\bullet$ & -520 & -333 & -3760 & 00 & -2 & -3760 & -60 & -100 & -376 & -376 \\
\hline SAF-4 & $\ddot{y}_{S}^{*}$ & 0 & -156 & -4170 & -5110 & -60 & -30 & -5110 & -520 & -860 & -5110 & -511 \\
\hline$A F-5$ & $s \sum Y$ & $\bullet$ & $-63 \bullet$ & -258 & -2380 & 00 & -2 & $-258 \mathrm{C}$ & -20 & -9 & 258 & -258 \\
\hline \multirow{2}{*}{ Index } & \multirow{2}{*}{\multicolumn{2}{|c|}{$\begin{array}{l}\text { Assess. } \\
\text { quantity }\end{array}$}} & \multicolumn{3}{|c|}{ Type of track section } & \multicolumn{3}{|c|}{ Track layout } & \multicolumn{3}{|c|}{ Speed } & \multirow{2}{*}{ MAX } \\
\hline & & & Cv & $T_{r}$ & St & RS & RM & RL & $\min$ & Vref & Vmax & \\
\hline FAT-1 & $Q$ & 0 & $-4 \odot$ & -170 & -550 & 00 & 00 & -550 & -10 & -20 & $-55 \odot$ & -55 \\
\hline FAT-2 & $Y_{q s t}$ & 0 & 0 & - & - & 0 & 0 & - & 00 & 00 & 00 & 0 \\
\hline$=A T-3$ & $Q_{q s t}$ & 0 & 0 & - & - & 00 & 0 & - & 00 & 00 & 00 & 0 \\
\hline \multirow{2}{*}{ Index } & \multirow{2}{*}{\multicolumn{2}{|c|}{$\begin{array}{l}\text { Assess. } \\
\text { quantity }\end{array}$}} & \multicolumn{3}{|c|}{ Type of track section } & \multicolumn{3}{|c|}{ Track layout } & \multicolumn{3}{|c|}{ Speed } & \multirow{2}{*}{ MAX } \\
\hline & & & Cv & $\operatorname{Tr}$ & St & RS & RM & RL & Vmin & Vref & Vmax & \\
\hline COM-1 & $\ddot{y}_{q}^{*}$ & - & -173 & -608 & -7190 & -5 & $-31 \bullet$ & -719 & $-68 \bullet$ & $-107 \bigcirc$ & $-719 \bullet$ & -719 \\
\hline COM-2 & $\ddot{z}_{q}^{*}$ & 0 & -30 & -60 & 00 & $0 C$ & 00 & -60 & 00 & 00 & -60 & -6 \\
\hline COM-3 & $s \ddot{y}_{q}^{*}$ & 0 & -5300 & -1631 & $-2317 C$ & $13 \bullet$ & -50 & -2317 & -1420 & $-255 \bigcirc$ & -23170 & -2317 \\
\hline COM-4 & $s \ddot{z}_{q}^{*}$ & 0 & -30 & -80 & 00 & 00 & 00 & -80 & 00 & 00 & -80 & -8 \\
\hline COM-5 & $\ddot{y}_{q s t}^{*}$ & 0 & -1 & - & 0 & 00 & 00 & -10 & 00 & 00 & -10 & -1 \\
\hline
\end{tabular}

Variation range (P10; P90)from $12 \%$ to $140 \%$ of the reference value (P50).
Legend:
Low (Influence < 10\%);
C Moderate $(10 \% \leq$ Influence $<25 \%)$
- Noticeable $(25 \% \leq$ Influence $<50 \%$

- High $(50 \% \leq$ Influence $<75 \%)$; Very high (Influence $\geq 75 \%$ ).

TABLE 23 TOTAL VARIABILITY OF RESULTS: MOMENT OF INERTIA OF THE CARBODY AROUND THE Z AXIS 


\begin{tabular}{|c|c|c|c|c|c|c|c|c|c|c|c|c|}
\hline \multirow{2}{*}{ Index } & \multirow{2}{*}{$\begin{array}{l}\text { Assess. } \\
\text { quantity }\end{array}$} & \multicolumn{4}{|c|}{ Type of track section } & \multicolumn{3}{|c|}{ Track layout } & \multicolumn{3}{|c|}{ Speed } & \multirow{2}{*}{ MAX } \\
\hline & & & & $\operatorname{Tr}$ & St & RS & RM & RL & Vmin & Vref & Vmax & \\
\hline SAF-1 & $(\Sigma Y)_{2 m}$ & - & $-93 \bullet$ & -190 & 80 & 120 & $-18 \bigcirc$ & -930 & $-6 c$ & $-11 \bullet$ & -93 & -93 \\
\hline SAF-2 & $(Y / Q)_{2 m}$ & 0 & -910 & -32 & ( & -320 & -120 & -910 & -210 & -270 & -910 & -91 \\
\hline SAF-3 & $\ddot{y}_{s}^{+}$ & 0 & $-147 \bigcirc$ & -800 & 70 & 10 & -20 & -1470 & 30 & -40 & -1470 & -147 \\
\hline SAF-4 & $\ddot{y}_{s}^{*}$ & 0 & -90 & -70 & $-13 \odot$ & -130 & -70 & -96 & -130 & -100 & -96 & -13 \\
\hline SAF-5 & $s \sum Y$ & - & -2270 & -90 & 80 & 00 & $0 \bullet$ & -2270 & -30 & $3 \bullet$ & -227 & -227 \\
\hline \multirow{2}{*}{ Index } & \multirow{2}{*}{$\begin{array}{l}\text { Assess. } \\
\text { quantity }\end{array}$} & \multicolumn{4}{|c|}{ Type of track section } & \multicolumn{3}{|c|}{ Track layout } & \multicolumn{3}{|c|}{ Speed } & \multirow{2}{*}{ MAX } \\
\hline & & \multicolumn{2}{|r|}{ Cv } & $\operatorname{Tr}$ & St & RS & RM & RL & Vmin & Vref & Vmax & \\
\hline FAT-1 & $Q$ & 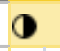 & 460 & 340 & 40 & 460 & 410 & 410 & 230 & 350 & 460 & 46 \\
\hline FAT-2 & $Y_{q s t}$ & 0 & -7 & - & 0 & -70 & 3 & - & -60 & -70 & -70 & -7 \\
\hline FAT-3 & $Q_{q s t}$ & 0 & 22 & - & ○ & 220 & 19 & - & 110 & 160 & 220 & 22 \\
\hline \multirow{2}{*}{ Index } & \multirow{2}{*}{\multicolumn{2}{|c|}{$\begin{array}{l}\text { Assess. } \\
\text { quantity }\end{array}$}} & \multicolumn{3}{|c|}{ Type of track section } & \multicolumn{3}{|c|}{ Track layout } & \multicolumn{3}{|c|}{ Speed } & \multirow{2}{*}{ MAX } \\
\hline & & & $\mathrm{Cv}$ & - & St & RS & RM & RL & Vmin & Vref & Vmax & \\
\hline COM-1 & $\ddot{y}_{q}^{*}$ & (1) & -320 & -80 & $-13 \odot$ & -130 & -70 & $-32 \odot$ & -130 & -90 & -320 & -32 \\
\hline COM-2 & $\ddot{z}_{q}^{*}$ & 0 & -20 & -30 & -30 & -10 & -20 & -30 & -30 & -30 & -20 & -3 \\
\hline COM-3 & $s \ddot{y}_{q}^{*}$ & 0 & -1120 & -220 & -28 & -28 & -170 & -1120 & $-28 \theta$ & -200 & -1120 & -112 \\
\hline COM-4 & $s \ddot{z}_{q}^{*}$ & 0 & -50 & -50 & -60 & 10 & -40 & -60 & -60 & -50 & -40 & -6 \\
\hline COM-5 & $\ddot{y}_{q s t}^{*}$ & 0 & -1 & - & 0 & 10 & 10 & -10 & -10 & 10 & -10 & -1 \\
\hline Variation & n range $(F$ & $10 ; P$ & P90)from & $80 \%$ to & $124 \%$ of & $f$ the referen & nce value & (P50). & & & & \\
\hline Legend: & & $O L$ & Low (Influen & $c e<10 \%)$; & () & Moderate (1 & $10 \% \leq$ Influe & nce $<25 \%$ & (1) No & Joticeable $\left(25^{\circ}\right.$ & $5 \% \leq$ Influen & $<50 \%$ \\
\hline & & ○ & High $(50 \% \leq$ & $\leq$ Influence $<$ & $<75 \%)$ & Very high (In & Influence $\geq 7$ & 75\%). & & & & \\
\hline
\end{tabular}

From these results, it can be concluded that:

- mc shows high influence for any study.

- IXc shows low influence for safety and track fatigue studies, and moderate influence for ride quality studies.

- IYc shows low influence for safety and track fatigue studies, and high influence for ride quality studies. Nevertheless, for ride quality studies it also shows low influence for RS track layout at any speed.

- IZc shows a very high influence for safety and ride quality studies, and a high influence for track fatigue studies. However, for track fatigue studies it only shows high influence with $\mathrm{RL}$ track layout at $\mathrm{Vmax}$, but a low influence in any other condition. It also shows low influence for safety studies with RS track layout at any speed.

- ZGc shows very high influence for safety and ride quality studies and noticeable influence for track fatigue studies.

\subsection{INFLUENCE OF THE INERTIAL PROPERTIES OF THE BOGIE}

The following tables show the influence obtained when analyzing the following inertial properties of the bogie:

- Mass of the bogie, mb (Table 25)

- Moment of inertia of the bogie around the $x$ axis, IXb

- Moment of inertia of the bogie around the $y$ axis, IYb

- Moment of inertia of the bogie around the $z$ axis, IZb (Table 26)

- Height of the centre of gravity of the bogie, ZGb

Those results related to IXb, IYb and ZGb were omitted, as they present low influence in all the analyzed scenarios. 


\begin{tabular}{|c|c|c|c|c|c|c|c|c|c|c|c|c|c|}
\hline \multirow{2}{*}{ Index } & \multirow{2}{*}{$\begin{array}{l}\text { Assess. } \\
\text { quantity }\end{array}$} & \multicolumn{4}{|c|}{ Type of track section } & \multicolumn{4}{|c|}{ Track layout } & \multicolumn{3}{|c|}{ Speed } & \multirow{2}{*}{ MAX } \\
\hline & & & $\mathrm{Cv}$ & $\operatorname{Tr}$ & St & RS & \multicolumn{2}{|c|}{ RM } & RL & Vmin & Vref & Vmax & \\
\hline AF-1 & $(\Sigma Y)_{2 m}$ & - & $113 \bullet$ & $231 \bullet$ & $265 c$ & & 40 & $9 \bullet$ & 2650 & $16 \oplus$ & $28 \bullet$ & 265 & 265 \\
\hline AF-2 & $Q)_{2 m}$ & () & $28 \bullet$ & 76 & $c$ & & 30 & $-4 \bullet$ & 760 & -40 & $7 \bullet$ & 76 & 76 \\
\hline AF-3 & $\ddot{\ddot{v}}^{+}$ & - & $127 \bullet$ & $315 \bullet$ & 2860 & & 20 & $6 \bullet$ & $315 \odot$ & 15 ( & $26 \bullet$ & 315 & 315 \\
\hline $\mathrm{F}-4$ & & () & $16 \oplus$ & $32 \bullet$ & 560 & & & $1 \bullet$ & 560 & 40 & $9 \bullet$ & 56 & 56 \\
\hline $\mathrm{F}-5$ & $s \Sigma Y$ & - & $86 \bullet$ & $210 \bullet$ & 1660 & & 10 & $3 \bullet$ & 2100 & 90 & $32 \bullet$ & 210 & 210 \\
\hline \multirow{2}{*}{ Index } & \multirow{2}{*}{$\begin{array}{l}\text { Assess. } \\
\text { quantity }\end{array}$} & \multicolumn{4}{|c|}{ Type of track section } & \multicolumn{4}{|c|}{ Track layout } & \multicolumn{3}{|c|}{ Speed } & \multirow{2}{*}{ MAX } \\
\hline & & & Cv & $\operatorname{Tr}$ & St & RS & & & RL & Vmin & ef & Vmax & \\
\hline $\mathrm{TT}-1$ & $Q$ & 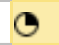 & $18 \oplus$ & $27 \bullet$ & 520 & & 60 & 70 & 520 & 70 & 90 & 52 & 52 \\
\hline T-2 & & 0 & 5 & - & 0 & & 50 & 4 & $\mathrm{O}$ & 40 & 40 & 50 & 5 \\
\hline $\mathrm{TT}-3$ & $Q_{q s t}$ & 0 & 6 & - & - & & 60 & 6 & - & 60 & 60 & 60 & 6 \\
\hline \multirow{2}{*}{ Index } & & \multicolumn{4}{|c|}{ Type of track section } & \multicolumn{4}{|c|}{ Track layout } & \multicolumn{3}{|c|}{ Speed } & \multirow{2}{*}{ MAX } \\
\hline & & & Cv & $\operatorname{Tr}$ & St & RS & & & RL & Vmin & ET & Vmax & \\
\hline$M-1$ & & () & $27 \bullet$ & $56 \bullet$ & 670 & & 0 & $2 \bullet$ & 670 & 50 & $9 \bullet$ & 67 & 67 \\
\hline M-2 & $\dddot{z}_{q}^{*}$ & 0 & 20 & 20 & 20 & & & 0 & 20 & 10 & 10 & 20 & 2 \\
\hline M-3 & $\ddot{*}^{*}$ & $\bullet$ & 82 & 173 & 2210 & & $1 \mathrm{C}$ & 20 & 2210 & 100 & 25 & 221 & 221 \\
\hline & 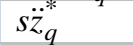 & 0 & 30 & 30 & 30 & & $1 C$ & 30 & 30 & 20 & 30 & 30 & 3 \\
\hline OOM-5 & $\ddot{y}_{q s t}^{*}$ & 0 & 0 & & 0 & & 00 & 00 & 00 & 00 & 00 & 00 & 0 \\
\hline
\end{tabular}

Variation range (P10; P90)from $68 \%$ to $190 \%$ of the reference value (P50).

Legend: $\quad$ Low (Influence $<10 \%)$; Moderate $(10 \% \leq$ Influence $<25 \%) \quad$ Noticeable $(25 \% \leq \operatorname{lnfluence}<50 \%$ - High $(50 \% \leq$ Influence $<75 \%)$; Very high (Influence $\geq 75 \%$ ).

TABLE 25 TOTAL VARIABILITY OF RESULTS: MASS OF THE BOGIE

\begin{tabular}{|c|c|c|c|c|c|c|c|c|c|c|c|c|c|}
\hline \multirow{2}{*}{ Index } & \multirow{2}{*}{$\begin{array}{l}\text { Assess. } \\
\text { quantity }\end{array}$} & \multicolumn{4}{|c|}{ Type of track section } & \multicolumn{4}{|c|}{ Track layout } & \multicolumn{3}{|c|}{ Speed } & \multirow{2}{*}{ MAX } \\
\hline & & & $\mathrm{cr}$ & $\operatorname{Tr}$ & St & RS & & RM & RL & Vmin & ef & Vmax & \\
\hline AF-1 & $(\Sigma Y)_{2 m}$ & $\boldsymbol{\bullet}$ & $55 \bullet$ & $78 \bullet$ & $145 C$ & & 10 & 2 & 1450 & $6 \bullet$ & $58 \bullet$ & 145 & 145 \\
\hline AF-2 & $(Q)_{2 m}$ & () & $47 \bullet$ & 117 & 0 & & 00 & 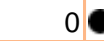 & 1170 & 20 & $36 \bullet$ & $17 \bullet$ & 117 \\
\hline FF-3 & $\ddot{\ddot{x}}^{+}$ & $\bullet$ & $73 \bullet$ & $112 \bullet$ & 1560 & & 00 & 2 & 1560 & $6 \bullet$ & $81 \bullet$ & 156 & 156 \\
\hline $\mathrm{F}-4$ & & () & 110 & 100 & 170 & & 00 & $0 c$ & 170 & 20 & $14 \odot$ & 170 & 17 \\
\hline F-5 & $s \Sigma Y$ & - & $71 \bullet$ & 112 & 1190 & & 00 & 2 & 1190 & $3 \bullet$ & 112 & $119 \bullet$ & 119 \\
\hline \multirow{2}{*}{ Index } & \multirow{2}{*}{$\begin{array}{l}\text { Assess. } \\
\text { quantity }\end{array}$} & \multicolumn{4}{|c|}{ Type of track section } & \multicolumn{4}{|c|}{ Track } & \multicolumn{3}{|c|}{ d } & \multirow{2}{*}{ MAX } \\
\hline & & & Cv & - & St & RS & & & RL & Vmin & v & Vmax & \\
\hline AT-1 & $Q$ & 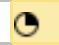 & 100 & 15 ( & 390 & & 00 & 00 & 390 & 10 & 100 & $39 \oplus$ & 39 \\
\hline T-2 & $Y_{q s t}$ & 0 & 0 & - & 0 & & 00 & 0 & 0 & 00 & 00 & 00 & 0 \\
\hline IT-3 & $Q_{q s t}$ & 0 & 0 & - & - & & 00 & 0 & 0 & 00 & 00 & 00 & \\
\hline & & \multicolumn{4}{|c|}{ Type of track section } & \multicolumn{4}{|c|}{ Track layout } & \multicolumn{3}{|c|}{ Speed } & \multirow{2}{*}{ MAX } \\
\hline & & & Cv & Tr & St & RS & & RM & RL & Vmin & ef & Vmax & \\
\hline M-1 & $\ddot{\ddot{r}}^{*}$ & () & $15 \odot$ & 180 & 250 & & 00 & 00 & 250 & D & 16 ( & $25 \oplus$ & 25 \\
\hline 2 & $\ddot{z}_{q}^{*}$ & 0 & 00 & 00 & 00 & & & $0 C$ & 00 & & 00 & 00 & 0 \\
\hline-3 & $\ddot{y}_{q}^{*}$ & $\bullet$ & $53 \bullet$ & $64 \bullet$ & 880 & & 00 & 10 & 880 & $4 \odot$ & $54 \bullet$ & 88 & 88 \\
\hline 4 & 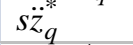 & 0 & 00 & 00 & 00 & & $0 \mathrm{C}$ & $0 C$ & 00 & 0 & 00 & 00 & 0 \\
\hline OOM-5 & $\ddot{y}_{q s t}^{*}$ & 0 & ? & & 0 & & 00 & $0 C$ & 20 & 00 & 00 & 20 & 2 \\
\hline
\end{tabular}

Variation range (P10; P90)from $64 \%$ to $251 \%$ of the reference value (P50).

Legend: $\quad O$ Low (Influence $<10 \%)$; Moderate $(10 \% \leq$ Influence $<25 \%) \quad$ Noticeable $(25 \% \leq$ Influence $<50 \%$

- High $(50 \% \leq$ Influence $<75 \%)$; Very high (Influence $\geq 75 \%$ ).

TABLE 26 TOTAL VARIABILITY OF RESULTS: MOMENT OF INERTIA OF THE BOGIE AROUND THE Z AXIS

From these results it can be concluded that:

- $\quad \mathrm{mb}$ shows very high influence for safety and ride quality studies, and high influence for track fatigue studies. Nevertheless, for any study it shows low influence with RS or RM track layouts at any speed. In addition, it also shows low influence for track 
fatigue and ride quality studies at Vmin with any track layout, as well as for track fatigue studies at Vref with any track layout.

- IXb shows low influence for any study.

- IYb shows low influence for any study.

- IZb shows very high influence for safety and ride quality studies, and noticeable influence for track fatigue studies. Nevertheless, for any study it shows low influence with RS or RM track layouts at any speed, as well as at Vmin with any track layout. In addition, it also shows low influence for track fatigue studies at Vref with any track layout.

- ZGb shows low influence for any study.

\subsection{INFLUENCE OF THE INERTIAL PROPERTIES OF THE WHEELSET}

The following tables show the influence obtained when analyzing the following inertial properties of the wheelset:

- Mass of the wheelset, mw (Table 27)

- Moment of inertia of the wheelset around the x/z axes, IXIZw (Table 28)

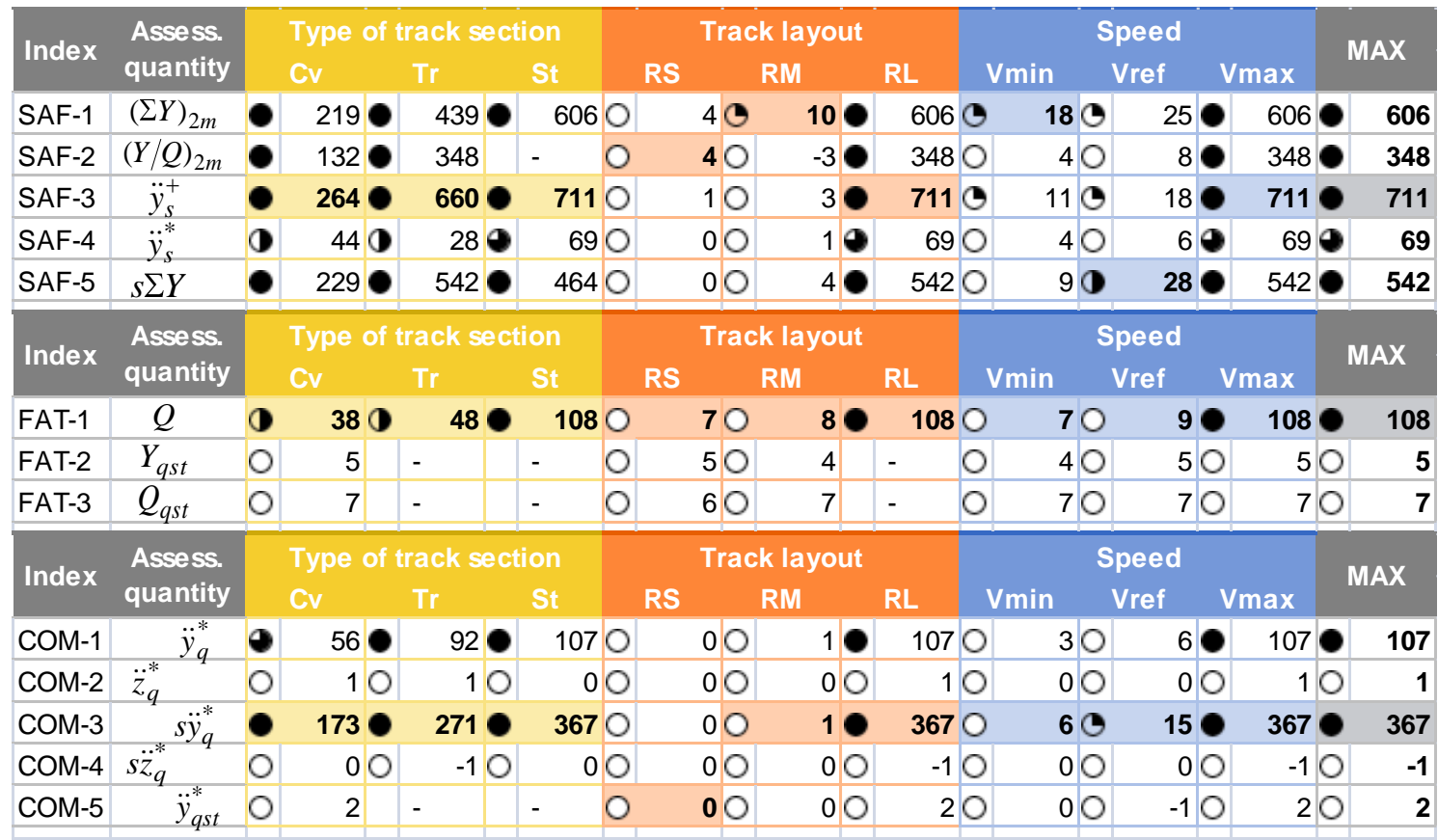

Variation range (P10; P90)from $63 \%$ to $140 \%$ of the reference value (P50).

\begin{tabular}{l|l|l|l} 
Legend: & Low (Influence $<10 \%) ; \quad$ Moderate $(10 \% \leq$ Influence $<25 \%)$ & Noticeable $(25 \% \leq$ Influence $<50 \%$ \\
& & High $(50 \% \leq$ Influence $<75 \%) ;$ & Very high (Influence $\geq 75 \%)$.
\end{tabular}

TABLE 27 TOTAL VARIABILITY OF RESULTS: MASS OF THE WHEELSET 


\begin{tabular}{|c|c|c|c|c|c|c|c|c|c|c|c|c|c|}
\hline \multirow{2}{*}{ Index } & \multirow{2}{*}{$\begin{array}{l}\text { Assess. } \\
\text { quantity }\end{array}$} & \multicolumn{4}{|c|}{ Type of track section } & \multicolumn{4}{|c|}{ Track layout } & \multicolumn{3}{|c|}{ Speed } & \multirow{2}{*}{ MAX } \\
\hline & & & Cv & $\operatorname{Tr}$ & St & & RS & RM & RL & Vmin & Vref & Vmax & \\
\hline SAF-1 & $\left(\sum Y\right)_{2 m}$ & 0 & 1110 & 258 & $525 C$ & & 10 & 20 & 5250 & 70 & $177 \bigcirc$ & 525 & 525 \\
\hline SAF-2 & $(Y / Q)_{2 m}$ & - & 840 & 334 & - & 0 & 10 & $0 \bullet$ & 3340 & 20 & $146 \bigcirc$ & 334 & 334 \\
\hline SAF-3 & $\ddot{y}_{s}^{+}$ & - & 132 & 3490 & $412 C$ & & 20 & 2 & 4120 & 90 & 3330 & 412 & 412 \\
\hline SAF-4 & $\ddot{y}$ & () & 180 & 130 & $36 C$ & 0 & 00 & 10 & 360 & 20 & 330 & 360 & () \\
\hline SAF-5 & $s \sum Y$ & - & 1470 & 310 & $283 C$ & & 00 & 20 & 3100 & 30 & 275 & 310 & 310 \\
\hline \multirow{2}{*}{ Index } & \multirow{2}{*}{\multicolumn{2}{|c|}{$\begin{array}{l}\text { Assess. } \\
\text { quantity }\end{array}$}} & \multicolumn{3}{|c|}{ Type of track section } & & \multicolumn{3}{|c|}{ Track layout } & \multicolumn{3}{|c|}{ Speed } & \multirow{2}{*}{ MAX } \\
\hline & & & Cv & $\operatorname{Tr}$ & St & & RS & RM & RL & Vmin & Vref & $V \max$ & \\
\hline FAT-1 & $Q$ & () & 19 & 920 & $246 C$ & & 10 & $0 \bullet$ & 2460 & 10 & 470 & 246 & 246 \\
\hline FAT-2 & $Y_{q s t}$ & 0 & 3 & - & - & 0 & 30 & 1 & - & 20 & 30 & & 0 \\
\hline FAT-3 & $Q_{q s t}$ & 0 & 0 & - & - & 0 & 00 & 0 & - & 00 & 00 & & 0 \\
\hline \multirow{2}{*}{ Index } & \multirow{2}{*}{\multicolumn{2}{|c|}{$\begin{array}{l}\text { Assess. } \\
\text { quantity }\end{array}$}} & \multicolumn{3}{|c|}{ Type of track section } & & \multicolumn{3}{|c|}{ Track layout } & \multicolumn{3}{|c|}{ Speed } & \multirow{2}{*}{ MAX } \\
\hline & & & Cv & $\operatorname{Tr}$ & St & & RS & RM & RL & Vmin & Vref & Vmax & \\
\hline COM-1 & 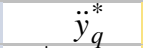 & () & $30 \bullet$ & $56 \bullet$ & $73 C$ & 0 & 00 & $0 \bullet$ & 730 & $2 \bullet$ & $56 \bullet$ & 73 & 73 \\
\hline COM-2 & $\ddot{z}_{q}^{*}$ & 0 & 20 & 20 & & 0 & 10 & 20 & -10 & 20 & 10 & & 0 \\
\hline COM-3 & $s \ddot{y}$ & ○ & 940 & $171 \bigcirc$ & $262 C$ & 0 & 10 & 10 & 2620 & 50 & 1740 & 262 & 262 \\
\hline COM-4 & $s \ddot{z}_{q}^{*}$ & 0 & 30 & 30 & $3 C$ & 0 & 20 & 30 & -10 & 30 & 20 & & 0 \\
\hline COM-5 & $\ddot{y}_{q s t}^{*}$ & 0 & -1 & - & - & 0 & 00 & 00 & -10 & 00 & -10 & & 0 \\
\hline Variation & n range & 10,1 & P90)from & $75 \%$ to & $187 \%$ & of th & he referenc & ice value & (P50). & & & & \\
\hline Legend: & & 0 & Low (Influen & ce $<10 \%)$; & & (-) $\mathrm{M}$ & Moderate (10 & $0 \% \leq$ Influe & nce $<25 \%$ & (1) $\mathrm{Nc}$ & Joticeable $\left(25^{\circ}\right.$ & $=\pi$ & $50 \%$ \\
\hline & & 0 & High (50\% & $\leq$ Influence $<$ & $<75 \%) ;$ & & /ery high (Inf & ffluence $\geq$ & & & & & \\
\hline
\end{tabular}

TABLE 28 TOTAL VARIABILITY OF RESULTS: MOMENT OF INERTIA OF THE WHEELSET AROUND THE X/Z AXES

From these results it can be concluded that:

- mw shows very high influence for any study. Nevertheless, for any study it shows low influence with RS track layout at any speed. For track fatigue and ride quality studies, it also shows low influence with RM track layout at any speed as well as at Vmin for any track layout. In addition, it also shows low influence for track fatigue studies at Vref with any track layout.

- IXw and IZw show very high influence for any study. Nevertheless, for any study they show low influence with RS or RM track layouts at any speed, as well as at Vmin with any track layout.

\subsection{FURTHER COMMENTS}

Influences of hundreds and even thousands of percent respect the related limit values were obtained for IZc, ZGc, mb, mw and IXw. For all these parameters, the safety index SAF-5 was also over $100 \%$ for RL track layouts at Vmax, thus indicating that the vehicle become unstable under such conditions, so conditioning the high influences found. However, lower influences may be found for these parameters if they had not been varied independently from the other inertial properties and from the geometry of their respective bodies, or even if they had been varied in lower steps.

\section{COMPARISON OF RESULTS OF THE SENSITIVITY ANALYSIS}

In this paragraph, the results obtained in the sensitivity analysis of all the parameters considered in this work are compared. The conclusions obtained from this analysis are also presented here. To have a more comprehensive view, results are grouped into three different categories: inertial properties of the carbody, inertial properties of the bogie and inertial properties of the wheelset. 
Within each group, the results were gathered in the same table, showing the characteristics of the most critical scenarios found when analyzing the influence of each parameter. The notations used for the output quantities shown in these tables were explained in Table 17.

\subsection{INFLUENCE OF THE INERTIAL PROPERTIES OF THE CARBODY}

Table 29 summarizes the characteristics of the most critical scenarios found when analyzing the influence of the inertial properties of the carbody.

mc

IXc

IYc

IZc

ZGc

Safety:

Track

\begin{tabular}{|c|c|c|c|c|c|}
\hline Index: & $\mathrm{SAF}-3, \ddot{\mathbf{y}}_{\mathbf{s}}^{+}$ & $\mathrm{SAF}-4, \ddot{\mathbf{y}}_{\mathbf{s}}^{*}$ & SAF-2, $\left(\frac{Y}{Q}\right)$ & $\mathrm{SAF}-4, \ddot{\mathbf{y}}_{\mathbf{s}}^{*}$ & SAF-5, $\mathbf{s} \boldsymbol{\Sigma} \mathbf{Y}$ \\
\hline Layout: & $\mathrm{RL}$ & RM & RM & $\mathrm{RL}$ & $\mathrm{RL}$ \\
\hline $\begin{array}{l}\text { Speed: } \\
\text { Influence: }\end{array}$ & $\begin{array}{l}\text { Vmax } \\
\Theta_{(65 \%)} \%\end{array}$ & $\bigcirc_{(-5 \%)}^{V \min }$ & $\begin{array}{l}\text { Vmax } \\
\bigcirc(-2 \%)\end{array}$ & $\begin{array}{l}\text { Vmax } \\
(-511\end{array}$ & $\begin{array}{l}\text { Vmax } \\
0_{(-22}\end{array}$ \\
\hline
\end{tabular}

fatigue:

$\begin{array}{llllll}\text { Index: } & \text { FAT-3, } \mathbf{Q}_{\text {qst }} & \text { FAT-2, } \mathbf{Y}_{\text {qst }} & \text { FAT-1, Q } & \text { FAT-1, Q } & \text { FAT-1, Q } \\ \text { Layout: } & \text { RS/M } & \text { RS } & \text { RM } & \text { RL } & \text { RS } \\ \text { Speed: } & \text { Vmax } & \text { Vmin } & \text { Vref } & \text { Vmax } & \text { Vmax } \\ \text { Influence: } & \boldsymbol{\Theta}(62 \%) & \bigcirc(1 \%) & \bigcirc_{(1 \%)} & \boldsymbol{(}(-55 \%) & \boldsymbol{(}(46 \%)\end{array}$

Ride

quality:

\begin{tabular}{|c|c|c|c|c|c|}
\hline Index: & $\mathrm{COM}-3, \boldsymbol{s} \ddot{y}_{\boldsymbol{q}}^{*}$ & $\mathrm{COM}-3, \boldsymbol{s} \ddot{y}_{q}^{*}$ & $\mathrm{COM}-4, \boldsymbol{s} \ddot{z}_{q}^{*}$ & $\mathrm{COM}-3, \boldsymbol{s} \ddot{y}_{\boldsymbol{q}}^{*}$ & $\mathrm{COM}-3, \boldsymbol{s} \ddot{y}_{\boldsymbol{q}}^{*}$ \\
\hline Layout: & $\mathrm{RL}$ & RM & $\mathrm{RL}$ & $\mathrm{RL}$ & $\mathrm{RL}$ \\
\hline $\begin{array}{l}\text { Speed: } \\
\text { Influence: }\end{array}$ & $\begin{array}{l}\text { Vmax } \\
\Theta(-66 \%)\end{array}$ & $\begin{array}{l}\mathrm{O}_{(-14}^{\mathrm{min}} \\
(-14)\end{array}$ & $\begin{array}{l}\text { Vmax } \\
\Theta_{(-74 \%)} \%\end{array}$ & $\begin{array}{l}\text { Vmax } \\
(-2317 \%)\end{array}$ & $\begin{array}{l}\text { Vmax } \\
(-112 \%)\end{array}$ \\
\hline
\end{tabular}

In view of these results, the most sensitive parameter is IZc, followed by ZGc, both with very high influence for safety and ride quality studies and with respectively high and noticeable influence for track fatigue studies, the worst results being found when running on the RL track layout at Vmax; they are followed by mc, with high influence for any study, the worst results being found when running at Vmax. The least sensitive parameters are IXc and IYc, both with low influence for safety and track fatigue studies, but with respectively moderate and high influence for ride quality studies.

\subsection{INFLUENCE OF THE INERTIAL PROPERTIES OF THE BOGIE}

Table 30 summarizes the characteristics of the most critical scenarios found when analyzing the influence of the inertial properties of the bogie. 


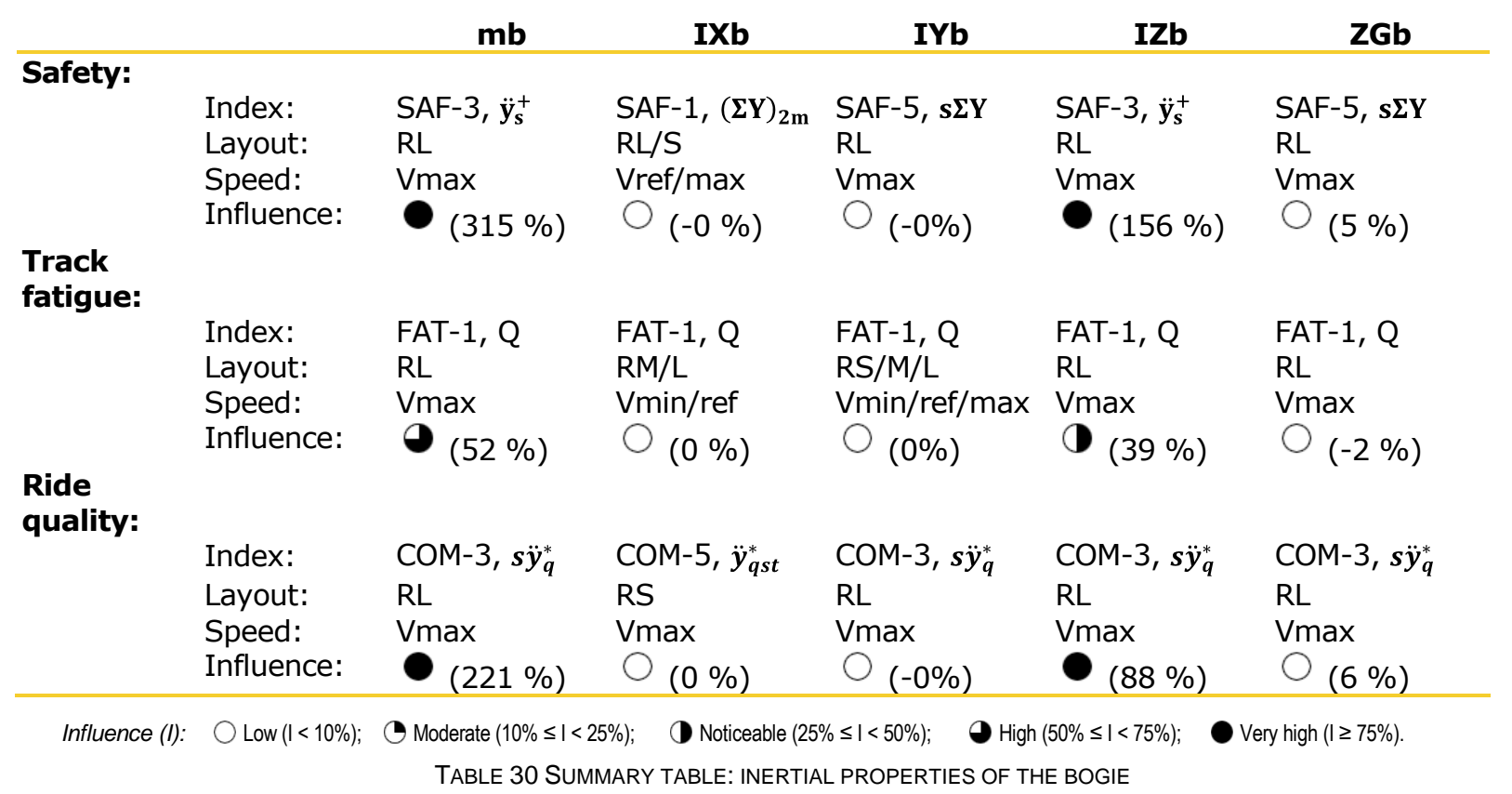

In view of these results, the most sensitive parameter is mb, closely followed by IZb, both with very high influence for safety and ride quality studies and with respectively high and noticeable influence for track fatigue studies, the worst results being found when running on the RL track layout at Vmax; the remaining parameters have low influence for safety, track fatigue and ride quality.

\subsection{INFLUENCE OF THE INERTIAL PROPERTIES OF THE WHEELSET}

Table 31 summarizes the characteristics of the most critical scenarios found when analyzing the influence of the inertial properties of the wheelset.

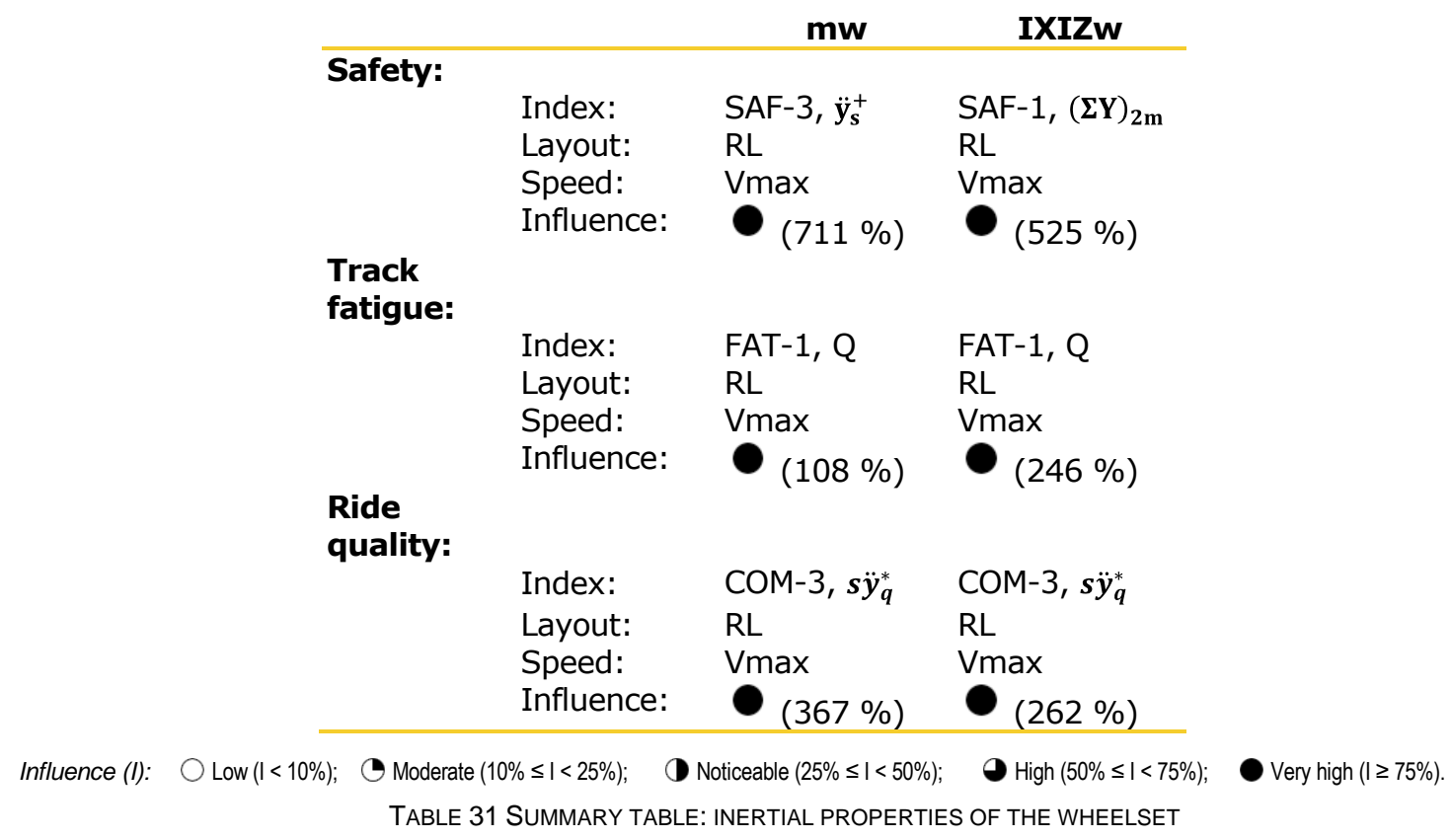

In view of these results, all the three parameters considered, mw, IXw and IZw show very high influence for any study, the worst results being found when running on the $R L$ track layout at Vmax. 


\subsection{ASYMMETRIES}

In some cases, the influence may be low when the parameter considered is reduced from the reference value to the percentile $10\left(\operatorname{lnf}_{10}\right)$, but may be high when the parameter is increased from the reference value to the percentile $90\left(\operatorname{lnf}_{90}\right)$. These asymmetries cannot be addressed from the previous tables, but can be appreciated in the graphical representations (similar to Figure 7). The following asymmetries were found in the data analyzed, with the ratio between both influences being even more than ten in some cases:

- IZc: $\operatorname{Inf}_{10}>>\operatorname{Inf}_{90}$ for $\mathrm{RL}$ track layout at Vmax, for indexes SAF-1/2/3/4/5 and COM-1/3 on any type of track section, and for index FAT-1 on straight track.

- $\mathrm{mb}, \mathrm{IZb}, \mathrm{mw}$, IXIZw: $\operatorname{Inf}_{90}>>\operatorname{Inf}_{10}$ for $\mathrm{RL}$ track layout at Vmax, for indexes SAF-1/2/3/4/5 and COM-1/3 on any type of track section, and for index FAT-1 on straight track.

- mc, ZGc: $\operatorname{Inf}_{10}>\operatorname{Inf}_{90}$ for RL track layout at Vmax, for index SAF-5 on straight and curved track sections, respectively.

- IXc, IYc, IXb, IYb, ZGb: no asymmetries were observed.

The standard EN-14363 establishes that the vehicle should be considered unstable if the index SAF-5 (s $\Sigma \mathrm{Y})$ is over $100 \%$. In accordance with this it was observed that, for those parameters with $\operatorname{Inf}_{10}>>\operatorname{Inf}_{90}$, when the parameter took the value P10, the vehicle was unstable for $\mathrm{RL}$ track layouts at Vmax. In a similar way, for those parameters with $\operatorname{Inf}_{90}>>\operatorname{Inf}_{10}$, when the parameter took the value P90, the vehicle was unstable for $R L$ track layouts at Vmax. And for those parameters with no asymmetries found, the critical speed was not reached in any simulation.

\subsection{ORDERING INERTIAL PROPERTIES BY INCREASING INFLUENCE}

In accordance with the previous results, generally speaking, it could be said that, of all the inertial properties, the most sensitive ones are the mass and the moment of inertia around the $z$ axis, while the least sensitive ones are the moments of inertia around the $x$ and $y$ axes. It could also be said that the moments of inertia of the carbody show a higher influence than those of the bogie, while the mass of the carbody shows a lower influence than the mass of the bogie.

Finally, the inertial properties of the vehicle were grouped considering the operating conditions under which their value could be estimated with a lesser degree of accuracy for future simulations, without significantly affecting the simulation results:

- IXb, IYb, ZGb: for any condition.

- IXc: for almost any condition.

- IZb, IXw, IZw: just for RS or RM track layouts, at any speed, and even for any track layout at Vmin.

- $\mathrm{mb}$ : just for RS or RM track layouts.

- IYc, mw: just for RS track layout.

- IZc: for some particular conditions.

- mc, ZGc: for no condition.

However, as already seen, those conditions in which it is admissible to assess the numerical value of a given parameter differ according to the study to be performed: safety, track fatigue or ride quality. Consequently, the value of the above parameters could be estimated with a lesser degree of accuracy for some other operating conditions. 


\section{CONCLUDING REMARKS}

In this work, the influence of the inertial properties of a railway vehicle was analyzed to assess their impact on the vehicle's dynamic behavior. As a whole, 12 different inertial properties were considered:

- mass, moments of inertia and height of the centre of gravity of the carbody;

- mass, moments of inertia and height of the centre of gravity of the bogie;

- mass and moments of inertia of the wheelset.

Due to the great number of uncertain parameters and external conditions (vehicle speed and track layout) to be considered, a simple approach, consisting in modifying the input parameters one at a time, was chosen to perform this study.

To undertake the study, a reference value, extracted from the railway vehicles database RVDynDB, was considered for each inertial property, thus defining an initial point in the space of input parameters:

Two additional values were assigned to each parameter, corresponding to the percentiles 10 and 90 of the data set stored in the vehicles database, hence exploring the 12-dimensional space by looking to both a lower and an upper value in each direction. These represent just $2 \cdot 12=24$ vertices of a hypercube with $2^{12}=4096$ vertices.

The 24 vertices considered were evaluated at 3 speeds and 3 track layouts and compared to the centre point, so that $24 \cdot 3 \cdot 3=216$ dynamic simulations were performed.

From these figures, it can be seen that the number of cases possible to test was necessary limited, thus conditioning the simplicity of the methodology to be used. This way, the study was focused on passenger vehicles, and the input parameters were modified one at a time, with just three values in each variation, even for parameters with large variation ranges, so assuming that the output quantities are smooth functions of the input parameters. Therefore, as previously stated, the conclusions that can be drawn are also limited from a quantitative point of view, but they can provide a qualitative idea about which influence quantities need to be addressed with particular care when performing simulations addressing a specific problem.

After processing the results of the simulations, the vehicle inertial properties were ordered by increasing influence. It was concluded that, of all the inertial properties, those showing highest influences are the mass and the moment of inertia around the $z$ axis. These results could be expected, as the former parameter helps to keep the train on the track and prevent derailment, while the latter is related with yaw motions, which are the most significant for a railway vehicle. On the other hand, the least sensitive parameters are the moments of inertia around the $x$ and $y$ axes.

The inertial properties of the vehicle were also grouped considering the operating conditions under which their value could be estimated with a lesser degree of accuracy for future simulations, without significantly affecting the simulation results:

- IXb, IYb, ZGb: for any condition.

- IXc: for almost any condition, except for some ride quality indexes.

- IZb, IXw, IZw: just for RS or RM track layouts, at any speed, and even for any track layout at $V \min$.

- $\mathrm{mb}$ : just for RS or RM track layouts.

- IYc, mw: just for RS track layout.

- IZc: just for some particular combinations of study, track layout and speed.

- mc, ZGc: for no condition. 
Though it was not considered in this analysis, it should be pointed out that, in fact, some inertial parameters are interconnected to each other. For instance, if one moment of inertia is well known, the other two moments of inertia of the same body would have a lower initial uncertainty. Nevertheless, the results found in this study could be useful when not all the data required to undertake a future simulation job are initially known, and there are no possibilities of testing. Such situations may arise, for instance, when the components to be modelled were manufactured by third parties or even when the vehicle to be analyzed was manufactured many years ago, as sometimes happens when dealing with derailment reconstructions. In such situations, the previous results could help to decide whether to accept or not any possible request to undertake a dynamic analysis for a vehicle with some unknown parameters.

Further development of the work proposed here might consist in varying the parameters found to be most important in smaller steps or, even further, in undertaking a probabilistic approach to consider simultaneous variations of the uncertain input parameters. In fact, from the results obtained, the number of parameters to be considered to undertake such probabilistic approach could be reduced. This way, quantitative and more accurate results could be obtained with a considerable lower computational cost than considering all the uncertain input parameters.

\section{REFERENCES}

1. Suarez, Berta. Metodología Analitica para el Estudio de Sensibilidades Aplicado a Modelos de Simulación Dinámica de Vehículos Ferroviarios, desde el Punto de Vista de la Seguridad, la Fatiga de Vía y la Calidad de Marcha. Madrid : Sección de Publicaciones de la Escuela Técnica Superior de Ingenieros Industriales, 2010. 978-84-693-2329-8.

2. Suarez, B., Mera, J.M. y Muneta, M.L. Sensitivity analysis to assess the impact of the elastic properties of railway vehicle suspensions on the vehicle's dynamic behaviour. in preparation.

3. Suarez, B., Felez, J. y Lozano, J.A. Sensitivity analysis to assess the impact of the rolling properties of railway vehicles on the vehicle's dynamic behaviour. Suarez, B.; Felez, J.; Lozano, J.A.; Rodriguez, P., in preparation.

4. Mazzola, Laura y Bruni, Stefano. Effect of suspension parameter uncertainty on the dynamic behaviour of railway vehicles. Applied Mechanics and Materials. 2012, Vol. 104, págs. 177-185.

5. Sandu, Adrian, Sandu, Corina y Ahmadian, Mehdi. Modeling multibody systems with uncertainties. Part I: Theoretical and computational aspects. Multibody System Dynamics. 2006, Vol. 15, págs. 373-395.

6. Suarez, B., Sanz, J.D. y Felez, J. Hierarchical classification of railway vehicles by the application of taxonomic analysis techniques. Probabilistic Engineering Mechanics. under review.

7. Suarez, B., Felez, J. y Sanz, J.D. Proposal of a Reference Model for Dynamic Sensitivity Analysis of Long-Distance Railway Passenger Cars. Probabilistic Engineering Mechanics. under review.

8. - XML based language for data exchange of rail vehicle dynamic simulation models. Application on a model database generation. Vehicle System Dynamics. under review.

9. UIC. UIC-518, Testing and Approval of Railway Vehicles from the Point of View of their Dynamic Behaviour - Safety - Track Fatigue - Ride Quality. 2003.

10. CEN. EN 14363, Aplicaciones Ferroviarias - Ensayos para la Aceptación del Comportamiento Dinámico de los Vehículos Ferroviarios - Ensayos en Línea y en Parada. 2007. 
11. Diedrichs, B., y otros. Vehicle Dynamics of a High-Speed Passenger Car due to Aerodynamics Inside Tunnels. Journal of Rail and Rapid Transit. 2007, Vol. 221, págs. 527-545.

12. Garg, V. K. y Dukkipati, R. V. Dynamics of Railway Vehicle Systems. s.1. : Academic Press, 1984. 0122759508.

13. Giménez, José Germán. Estabilidad en Dinámica Ferroviaria. II Curso de Especialización en Tecnologías Ferroviarias. Madrid : CITEF, 2001.

14. Ahmadian, Mehdi y Yang, Shaopu. Effect of System Nonlinearities on Locomotive Bogie Hunting Stability. Vehicle System Dynamics. 1998, Vol. 29, págs. 365-384.

15. Stichel, Sebastian. Limit Cycle Behaviour and Chaotic Motions of Two-Axle Freight Wagons with Friction Damping. Multibody System Dynamics. 2002, Vol. 8, págs. 243-255.

16. Wickens, Alan. H. Fundamentals of Rail Vehicle Dynamics: Guidance and Stability. s.1. : Swets \& Zeitlinger, 2003. 90-265-1946-X.

17. Analysis of Hopf Bifurcation in Rail Vehicle Dynamics. Yang, Shaopu y Ahmadian, Mehdi. Copenhagen (Denmark) : s.n., 1999. Proceedings of the Third European Nonlinear Oscillations Conference (ENOC).

18. Influence of Bogie to Car Body Connection Parameters on Stability and Curving of Freight Vehicles. Boronenko, Yu. P. y Orlova, S. M. [ed.] I. Zovory. Budapest (Hungary) : s.n., 2004. Proceedings of the 6th International Conference on Railway Bogies and Running Gears. págs. 67-72.

19. Boronenko, Y., Orlova, A. y Rudakova, E. Influence of Construction Schemes and Parameters of Three-Piece Freight Bogies on Wagon Stability, Ride and Curving Qualities. Vehicle System Dynamics Supplement. 2006, Vol. 44, págs. 402-414.

20. He, Yuping y Mcphee, John. Optimization of Curving Performance of Rail Vehicles. Vehicle System Dynamics. 2005, Vol. 43, págs. 895-923.

21. Simulation as a Tool for Assessing the Match between Track and Vehicle Standards. Iwnicki, S. D y Bezin, Y. London : s.n., 2001. Infrarail.

22. Real Time Vampire - Derailment Risk Indicator and Automatic Track Geometry Accuracy Assessment. Patko, S., Hope, K. y Gilbert, B. Montréal (Canada) : s.n., 2006. 7th World Congress on Railway Research.

23. Toma, Elton Edward. A Computer Model of a Train Derailment. Department of Mechanical Engineering, Queen's University. Ontario (Canada) : s.n., 1998. Thesis.

24. Dukkipati, R. V. y Dong, R. Idealized Steady State Interaction between Railway Vehicle and Track. 1999, Vol. 213, págs. 15-29.

25. Johansson, A. y Nielsen, J. C. O. Out-of-Round Railway Wheels - Wheel-Rail Contact Forces and Track Response Derived from Field Tests and Numerical Simulations. Journal of Rail and Rapid Transit. 2003, Vol. 217, págs. 135-146.

26. Stiche1, S. On Freight Wagon Dynamics and Track Deterioration. Journal of Rail and Rapid Transit. 1999, Vol. 213, págs. 243-254.

27. Enblom, R. Two-Level Numerical Optimization of Ride Comfort in Railway Vehicles. Journal of Rail and Rapid Transit. 2006, págs. 1-11.

28. Mastinu, G. R. M., Gobbi, M. y Pace, G. D. Analytical Formulae for the Design of a Railway Vehicle Suspension System. Proceedings of the Institution of Mechanical Engineers: Part C. 2001, Vol. 215, págs. 683-698.

29. Panagin, Romano. La Dinamica del Veicolo Ferroviario. Torino : Editrice Universitaria Levrotto \& Bella, 1997.

30. Iwnicki, Simon. The Manchester benchmark for rail vehicle simulation. Vehicle System Dynamics. 1999, Vol. 31 (Suppl.), págs. 1-48. 
31. European Railway Research Institute - ERRI B 176/DT 290. $B$ 176/3 Benchmark Problem: Results and Assessment. Utrecht : s.n., 1993.

32. VOLPE Center. John A. Volpe National Transportation Systems Center. $L D$ Benchmark. [En línea] 2005.

http://www.volpe.dot.gov/coi/pis/work/archive/docs/ldbenchmark/report.pdf.

33. Esveld, C. Modern Railway Track. s.1. : MTR Production, 2001. 90-80032-3-3.

34. B-176, ORE (ERRI). Benchmark Problems for Computer Programs for Calculating Running Dynamics. Paper B176.95/08-81, Annex III-3.

35. López-Pita, Andrés. Infraestructuras ferroviarias. Barcelona : Edicions UPC, 2006. 8483018535.

36. Polach, Oldrich. On Non-Linear Methods of Bogie Stability Assessment using Computer Simulations. Journal of Rail and Rapid Transit. 2006, Vol. 220, págs. 13-27.

37. FRA. Passenger Equipment Safety Standards. 49CFR238 - Part 238. 2007. 